\title{
GLADSTONE GOULART
}

\section{O valor dos critérios de indicação da angiotomogafia no diagnóstico de lesões das artérias carótidas e vertebrais no trauma contuso}

Tese apresentada à Faculdade de Medicina da Universidade de São Paulo para obtenção do título de Doutor em Ciências

Área de concentração: Clínica Cirúrgica

Orientador: Prof. Dr. Renato Sérgio Poggetti

São Paulo 
Dados Internacionais de Catalogação na Publicação (CIP)

Preparada pela Biblioteca da

Faculdade de Medicina da Universidade de São Paulo

Creprodução autorizada pelo autor

\section{Goulart, Gladstone}

O valor dos critérios de indicação da angiotomografia no diagnóstico de lesões das artérias carótidas e vertebrais no trauma contuso / Gladstone Goulart. -- São Paulo, 2010.

Tese(doutorado)--Faculdade de Medicina da Universidade de São Paulo.

Departamento de Cirurgia.

Área de concentração: Clínica Médica.

Orientador: Renato Sérgio Poggetti.

Descritores: 1.Ferimentos não penetrantes 2.Artéria vertebral 3.Lesões das artérias carótidas 4.Diagnóstico 5.Tomografia computadorizada helicoidal 


\section{Dedicatória}

À minha família, pela minha formação pessoal e educacional. 


\section{Agradecimentos}

Ao Prof. Dr. Renato Sérgio Poggetti, pela oportunidade de realizar esta PósGraduação sob sua orientação e pelo exemplo de profissionalismo e ética que representa para nossa especialidade.

Ao Prof. Dr. Belchor Fontes, pela supervisão primorosa, empatia e pelas inestimáveis sugestões ao longo da elaboração dessa pesquisa.

À Profa. Dra. Rina Maria Pereira Porta, pelo exemplo de profissionalismo, pelas orientações e questionamentos que muito contribuíram na realização dessa pesquisa.

Ao Dr. Almerindo Lourenço de Souza Júnior, pelas sugestões, e profissionalismo.

Ao Dr. Gabriel Gattas, pela empatia, pelas sugestões primorosas no estudo das imagens das angiotomografias na área de Radiologia.

À Secretaria de Pós-Graduação da FMUSP, em especial à Eliane Mônico Gazetto Falconi, pelo inestimável auxílio nos trâmites e pelo constante apoio.

Ao Departamento de Cirurgia da Faculdade de Medicina que me permitiu fazer a pesquisa, coletando dados clínicos dos doentes nas enfermarias e unidade de tratamento intensivo do trauma, do Serviço de Cirurgia da Emergência da III Divisão de Clínica Cirúrgica do Hospital das Clínicas da FMUSP. 
Esta tese está de acordo com as seguintes normas, em vigor no momento da publicação:

Referências: Adaptado de International Committee of Medical Journals Editors (Vancouver).

Universidade de São Paulo, Faculdade de Medicina, Serviço de Biblioteca e Documentação. Guia de apresentação de dissertações, teses e monografias da FMUSP. Elaborado por Annelise Carneiro da Cunha, Maria Julia A.L. Freddi, Maria F. Crestana, Marinalva de S. Aragão, Sueli C. Cardoso, Valéria Vilhena. 2a ed. São Paulo: Serviço de Biblioteca e Documentação; 2005.

Abreviaturas dos títulos dos periódicos de acordo com List of Journals Indexed in Index Medicus. 


\section{Sumário}

Lista de Abreviaturas

Lista de Tabelas

Lista de Figuras

Resumo

Summary

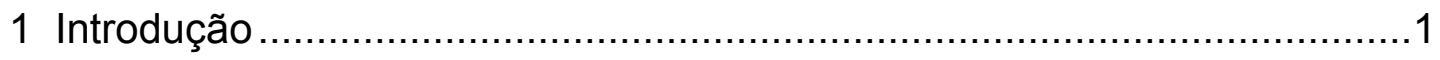

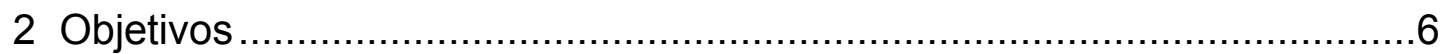

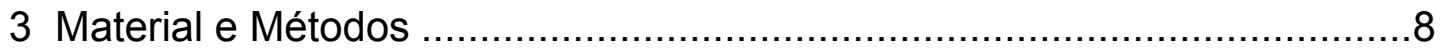

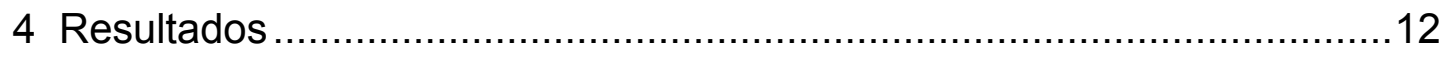

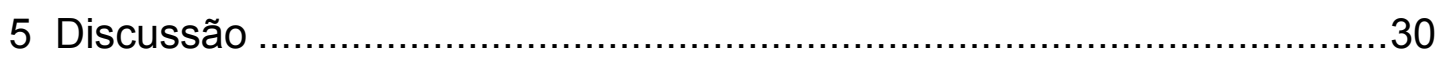

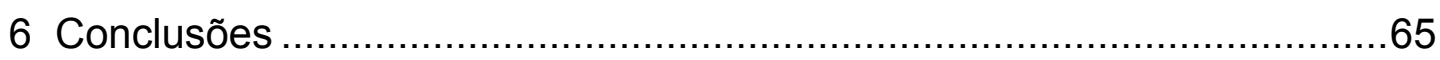

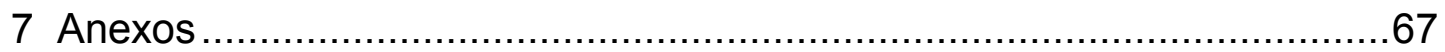

Anexo 1 - Aprovação pela Comissão de Ética para Análise de Projetos de Pesquisa - CAPPesq - Hospital das Clínicas da Faculdade de Medicina da Universidade de São Paulo ...68

Anexo 2 - Termo de Consentimento Livre e Esclarecido ......................69

Anexo 3 - Protocolo de identificação do doente com risco de lesão de vasos cervicais em trauma contuso .............................72

Anexo 4 - Planilha dos dados clínicos dos 100 doentes..................... 74

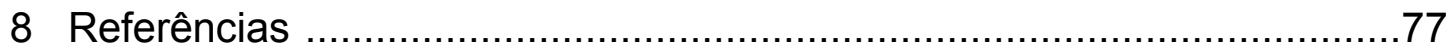


Listas 


\section{Lista de Abreviaturas}

$\begin{array}{ll}\text { FC } & \text { frequência cardíaca } \\ \text { FR } & \text { frequência respiratória } \\ \text { GCS } & \text { Glasgow coma score (escore na escala de coma de Glasgow) } \\ \text { Irpm } & \text { incurssões respiratórias por minuto } \\ \text { ISS } & \text { Injury Severity Score (escore de gravidade de lesão) } \\ \text { LCCV } & \text { lesões contusas de artérias carótidas e vertebrais } \\ \text { mmHg } & \text { milímetros de mercúrio } \\ \text { PAD } & \text { pressão arterial diastólica } \\ \text { PAS } & \text { pressão arterial sistólica } \\ \text { RTS } & \text { Revised Trauma Score (escore revisado de trauma) } \\ \text { TRISS } & \text { Trauma and Injury Severity Score } \\ \text { TVP } & \text { trombose venosa profunda }\end{array}$




\section{Lista de Tabelas}

Tabela 1 - Tempo entre admissão e a realização da angiotomografia por grupo

Tabela 2 - Sexo e Idade em 100 doentes submetidos a angiotomografia cervical......................................................14

Tabela 3 - Mecanismos de trauma em 100 doentes submetidos à angiotomografia cervical..................................................16

Tabela 4 - Sinais vitais em 100 doentes submetidos à angiotomografia cervical....................................................18

Tabela 5- Índice de gravidade em 100 doentes submetidos à angiotomografia cervical....................................................20

Tabela 6 - Número de vezes de aparecimento de critérios de inclusão no estudo em 100 doentes submetidos à angiotomografia cervical

Tabela 7 - Critérios de inclusão por grupo em 100 doentes submetidos à angiotomografia cervical

Tabela 8 - Outras lesões encontradas fora da região cervical em 100 doentes submetidos a angiotomografia cervical.

Tabela 9 - Lesões das artérias carótidas e vertebrais no Grupo II $\mathrm{n}=23$ doentes

Tabela 10 - Graus das lesões das artérias carótidas e vertebrais em 23 doentes do Grupo II.

Tabela 11 - Comparação entre as mortalidades do Grupo I e do Grupo II

Tabela 12 - Comparação das probabilidades de sobrevida pelo TRISS entre os Grupos de doentes que sobreviveram (79) e que morreram (21) dos 100 doentes do estudo

Tabela 13 - Comparação entre o percentual real de sobreviventes com o percentual de sobrevida calculada pelo TRISS 


\section{Lista de Figuras}

Figura 1 - Desenho de artérias carótidas e vertebrais e suas relações com a coluna cervical

Figura 2 - Desenho de trauma contuso por cinto de segurança em região cervical

Figura 3 - Desenho de subluxação de $\mathrm{C}_{3}$ comprimindo a artéria carótida interna esquerda.

Figura 4 - Desenho de fratura do processo espinhoso e forame transverso comprimindo a artéria vertebral esquerda

Figura 5 - Desenho de hiperextensão e flexão do pescoço comprimindo a artéria carótida interna direita

Figura 6 - Desenho de fratura de mandíbula comprimindo a artéria carótida interna direita

Figura 7 - Desenho de fratura de face tipo LeFort II .............................35

Figura 8 - Desenho de fratura de face tipo LeFort III ............................36

Figura 9 - $\quad$ Angiotomografia de fratura de base de crânio ........................37

Figura 10 - Angiotomografia de oclusão da artéria caródia interna no seu terço distal

Figura 11A - Desenho de lesão da parede arterial da artéria carótida interna após contusão cervical causando embolizações

Figura 11B - Angiotomografia dos vasos cervicais em perfil identificando artéria carótida interna esquerda com dissecção > 25\% à esquerda

Figura 12A - Angiotomografia dos vasos cervicais: oclusão e dissecção da artéria carótida interna a partir do seu terço médio com oclusão distal.

Figura 12B- Angiotomografia Cervical com dissecção da artéria carótida comum direita

Figura 13A- Angiotomografia Cervical (janela óssea), corte sagital identificando fragmento ósseo no interior do forame transverso esquerdo 
Figura 13A- Angiotomografia Cervical (janela óssea), corte sagital identificando fragmento ósseo no interior do forame transverso esquerdo

Figura 13B- Angiotomografia Cervical em perfil com dissecção e oclusão da artéria vertebral esquerda

Figura 13C - Angiotomografia Cervical com corte axial nível imediatamente acima da transecção, não demonstrando a artéria vertebral esquerda neste nível

Figura 14 - Angiotomografia Cervical identificando secção da artéria vertebral esquerda próxima da sua origem 


\section{Resumo}

Goulart G. O valor dos critérios de indicação da angiotomografia no diagnóstico de lesões das artérias carótidas e vertebrais no trauma contuso [tese]. São Paulo: Faculdade de Medicina, Universidade de São Paulo; 2010. $71 \mathrm{p}$.

Introdução: As lesões contusas de artérias carótidas e vertebrais (LCCV) não são muito frequentes, porém podem apresentar repercussões graves. A incidência desse tipo de lesão é difícil de ser avaliada porque os doentes podem estar neurologicamente assintomáticos quando atendidos no pronto socorro ou podem apresentar sintomas que são atribuídos ao trauma de crânio ou a outras lesões associadas. Estatísticas recentes apontam uma incidência de $0,24 \%$ a $0,33 \%$ em doentes traumatizados portadores de algum sintoma neurológico. No Brasil não existem trabalhos de nosso conhecimento que tenham estudado a incidência das LCCV. Por outro lado, a real morbidade e mortalidade das LCCV não estão claramente determinadas, nem mesmo na literatura internacional. Os objetivos deste estudo foram: a) avaliar a incidência de LCCV em 100 doentes vítimas de trauma contuso submetidos à angiotomografia cervical, utilizando parâmetros obtidos da avaliação clínica inicial e das tomografias de crânio e da região cervical e b) verificar quais os critérios de indicação da angiotomografia cervical que mais se correlacionam com a presença de LCCV no serviço de trauma de hospital quaternário brasileiro. Material e Método: Durante o período de trinta meses a partir de julho de 2006, todos os doentes admitidos no Pronto-Socorro do Hospital das Clínicas da Faculdade de Medicina da Universidade de São Paulo, com trauma cervical fechado, com potencial risco de lesão dos vasos cervicais apresentando défice neurológico não justificado pela tomografia computadorizada de crânio, infarto cerebral, hematoma cervical estável, epistaxe volumosa, anisocoria/sinal de Horner, escore na escala de coma de Glasgow abaixo de 8 sem achados justificativos pela tomografia, fratura de coluna cervical, fratura de base de crânio, fratura de face (Le Forte II ou III), sinal do cinto de segurança acima da clavícula, frêmito ou sopro cervical, foram incluídos no estudo. Os doentes foram encaminhados para a angiotomografia cervical para diagnóstico das LCCV. Foram analisados também mecanismo de trauma, sexo, idade, gravidade do trauma, gravidade das LCCV, tipo de tratamento e evolução. Os doentes foram divididos em dois grupos: sem LCCV (Grupo I) e com LCCV (Grupo II). Os dados analisados são apresentados como média e desvio padrão da média e as análises estatísticas foram realizadas com os testes de Qui-Quadrado e Exato de Fisher, e o teste de Mann-Whitney. Foi usado um nível de significância de 5\% (p-valor $\leq 0,05)$. Resultado: Foram atendidos 2.467 doentes vítimas de trauma contuso. Em 100 doentes que apresentaram critérios para inclusão, no estudo a angiotomografia identificou 23 com LCCV, 17 do sexo masculino e 6 do sexo feminino. A idade média foi de $34,81 \pm 14,84$ anos. Colisão de auto $(49 \%)$ e atropelamento $(24 \%)$ foram os 
mecanismos de trauma mais frequentes seguidos de queda de grande altura (18\%), e outros mecanismos (9\%). Dez doentes tiveram lesão de carótida interna, 2 doentes com lesão de carótida comum, onze doentes com lesão de vertebral. Sete doentes apresentaram lesão arterial grau I, 10 grau II, 4 grau IV e I grau V e uma fístula de carótida. Sete $(30,4 \%)$ dos 23 doentes com LCCV apresentavam fratura de vértebras cervicais e $11(47,8 \%)$ apresentavam fratura de face (LeFort II e III). Dezessete doentes foram tratados clinicamente e seis doentes foram submetidos a tratamento endovascular (um stent e cinco embolizações). Conclusão: Os critérios utilizados neste estudo permitiram o diagnóstico de LCCV em $0,93 \%$ dos casos, sendo que tais lesões ocorreram nos traumatizados mais graves, e não influenciaram a morte na população estudada.

Descritores: 1) Ferimentos não Penetrantes 2) Artéria Vertebral 3) Lesóes das Artérias Carótidas 4) Diagnóstico 5) Tomografia Computadorizada Helicoidal 


\section{Summary}

Goulart G. Value of the criteria for indication of angiography in the diagnosis of carotid and vertebral arterial injuries in blunt trauma [thesis]. São Paulo: "Faculdade de Medicina, Universidade de São Paulo"; 2010. 71p.

Background: Blunt trauma of the carotid and vertebral arteries (LCCV) are infrequent, but may have serious repercussions. The incidence of this type of injury is difficult to evaluate as many patients are neurologically asymptomatic when assisted in emergency rooms, or with symptoms attributed to cranium trauma or to other associated injuries. Recent statistical data show an incidence of $0.24 \%$ to $0.33 \%$ traumatized patients that carry some neurological symptom, we are not aware of any papers in Brazil that have studied the occurrence of LCCV. On the other hand, the real morbidity and mortality are not clearly determined, not even in the international literature. The objectives of the current study were: a) to evaluate the incidence of carotid and vertebral artery injuries in 100 patients with blunt trauma subjected to cervical angiography, using parameters obtained from the initial clinical evaluation and tomography of the patients and $b$ ) to verify which criteria for recommending cervical angiography are most related to the presence of LCCV in the trauma services section in a Brazilian quaternary care hospital. Method: During thirty months, starting in July 2006, all patients admitted in the emergency room of Hospital das Clínicas da Faculdade de Medicina da Universidade de São Paulo, with blunt cervical trauma, with potential risk of injuries to cervical vessels that presented neurological deficit unexplained after cranial CT scan, cerebral infarction, stable cervical haematomas, severe epistaxis, anisocoria/sign of Horner's syndrome, Glasgow coma scores bellow 8 that are not explained by CT scan, cervical spine fracture, basilar skull fracture, facial fracture (Le Forte II or III), seatbelt signals above the clavicle, cervical hum or bruit were included in the study. The patients were subjected to cervical angiography in order to diagnose LCCV. There were analyzed the mechanisms of injuries, gender, age, severity of LCCV, type of treatment and outcome. The patients were divided into two groups: without LCCV (Group I) and with LCCV (Group II). The data analyzed are presented as mean minus standard deviation and the statistical analyzes were done using Chi-square and Fisher's exact tests, and the Mann-Whitney test. For date comparison, a p-value $\leq 0,05$ was considered significant. Results: 2.467 patients, victims of blunt trauma, were included in the study. In 100 patients that presented the criteria for the inclusion in the study, the angiography identified 23 with LCCV, 17 male and 6 female. The mean age was $34,81 \pm 14,84$ years. Car crash $(49 \%)$ and car-pedestrian accidents $(24 \%)$ were the most frequent mechanisms of injury, followed by falling from altitude $(18 \%)$, and other mechanisms (9\%). Ten patients suffered internal carotid artery injury, 2 patients with common carotid artery injury, and eleven patients with vertebral artery injury. Seven patients presented arterial injury level I, 10 level II, 4 level IV and 1 level $V$ and one carotid fistula. Seven $(30,4 \%)$ out of the 23 patients 
with LCCV presented cervical vertebrae fractures and $11(47,8 \%)$ presented facial fracture (LeFort II e III). Seventeen patients were treated clinically and six underwent endovascular treatment (one stent and five embolizations). Conclusion: The criteria used in this study have allowed the diagnosis of LCCV in $0,93 \%$ of the cases, those being such injuries that occurred in the most seriously traumatized patients, and did not lead to death in the studied population.

Descriptors: 1) Wounds Nonpenetrating 2) Vertebral Artery 3) Carotid Artery / Injuries 4) Diagnostic 5) Helical Computed tomography 


\section{Introdução}


As lesões contusas de artérias carótidas e vertebrais (LCCV) são infrequentes; no entanto, podem apresentar repercussões graves. A incidência dessas lesões é difícil de ser avaliada porque muitos doentes encontram-se sem sintomas neurológicos quando atendidos no ProntoSocorro embora com sintomas atribuídos ao trauma de crânio, ou a outras lesões associadas. Em dois terços dos doentes portadores dessas lesões, elas podem não ser diagnosticadas ${ }^{(1,2)}$. Estatísticas mais recentes apontam uma incidência dessas lesões em $0,24 \%$ a $0,33 \%$ em doentes traumatizados, que apresentam algum sintoma de comprometimento neurológico ${ }^{(3,4)}$. Portanto, o alto índice de suspeita é fundamental para o diagnóstico de tais lesões no trauma contuso cervical. No Brasil, não existem trabalhos de nosso conhecimento que tenham estudado a incidência das lesões traumáticas das artérias carótidas e vertebrais no trauma contuso. Dada à baixa incidência dessas lesões, sua real morbidade e mortalidade não estão claramente determinadas na literatura consultada. Ressalta-se que grande parte dessas lesões não é diagnosticada e tratada precocemente antes que ocorra um evento cerebral isquêmico ${ }^{(5)}$.

As lesões das artérias carótidas e vertebrais, são classificadas em graus que variam de I a ${ }^{(1)}$. As lesões grau I compreendem as irregularidades da luz da artéria ou as dissecções com estenose inferior a $25 \%$ da luz. As lesões grau II são as dissecções ou os hematomas 
intramurais com estenose igual ou maior do que $25 \%$ da luz do vaso bem como, os trombos intraluminais ou as placas elevadas na íntima. As lesões grau III são os pseudoaneurismas. As lesões grau IV são as oclusões. Finalmente, as lesões de grau $\bigvee$ são as secções com hemorragia.

Vários exames laboratoriais e de imagem são frequentemente solicitados nos serviços de emergência para avaliação do traumatizado. No entanto, exames de imagem para identificação de lesões de vasos cervicais não são feitos rotineiramente no atendimento inicial ao traumatizado. A arteriografia é considerada o exame "padrão ouro", para identificação dessas lesões vasculares, entretanto é invasiva e apresenta riscos que incluem complicações relacionadas ao local da punção, como os hematomas (1\% a $2 \%$, os pseudoaneurismas, as complicações sistêmicas que incluem a reação alérgica, a insuficiência renal pelo contraste,, e o acidente vascular cerebral, que ocorrem em menos de $1 \%$ dos casos. O Duplex Scan não é invasivo, tem $86 \%$ de sensibilidade, porém apresenta limitações na identificação das lesões arteriais, como da artéria carótida interna próxima à base do crânio, mas fornece evidências indiretas de lesões mais distais por detectar turbulência e outros distúrbios de fluxo sanguíneo, no caso de lesões que provocam estenose menor do que $60 \%$ da luz. A angiotomografia apresenta boa sensibilidade para identificação de lesões anatômicas em geral, podendo ser uma boa opção para estudo de lesões vasculares. Devese lembrar que a tomografia computadorizada é um método diagnóstico bastante utilizado, na avaliação inicial do traumatizado. Espera-se que os hospitais de referência para atendimento ao traumatizado grave tenham 
tomógrafo disponível 24 horas. Entretanto, a reconstrução das imagens para o estudo das lesões de vasos cervicais exige tempo extra e manipulação para construção de imagens em três dimensões com o uso de tomógrafos de multicanais. Por outro lado a existência de artefatos ósseos no canal carotídeo pode ser um fator que dificulta a identificação de lesões vasculares não muito evidentes ${ }^{(5,1,12,11)}$. A angiorressonância magnética tem a capacidade de formar imagens da cabeça e pescoço, simultaneamente, além de detectar infarto cerebral precoce, sem a utilização de contraste. Entretanto, este recurso ainda é indisponível em muitos hospitais, a realização do exame é demorada e a presença do campo magnético impede sua realização em doentes dependentes do ventilador mecânico e em portadores de fixações ortopédicas ${ }^{(5,1,6,12)}$.

Na década de 1990, com a utilização da arteriografia como método diagnóstico na população de risco para LCCV, foi demonstrado que essas lesões são raras, correspondendo a $1 \%$ de todos os traumas contusos admitidos no hospital. Diante da experiência limitada com LCCV nos centros de trauma, a literatura ainda é muito escassa no que se refere à padronização de métodos diagnósticos e de condutas terapêuticas para essas lesões. Não existe também a aceitação unânime das classificações existentes para as LCCV. Todas estas limitações apresentadas anteriormente restringem a formulação de um fluxograma prático, seguro e universal na condução desses casos ${ }^{(5)}$. 
Embora o melhor tratamento das LCCV ainda seja motivo de discussão, todas as modalidades de tratamento seja este clínico ou endovascular, prescindem do quadro clínico, da qualificação da equipe médica e, sobretudo da caracterização precisa da localização e da gravidade da lesão por método diagnóstico adequado. 
2 Objetivos

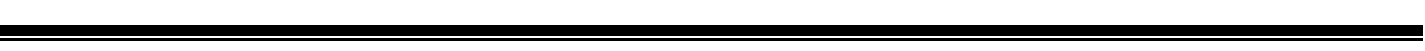


- Avaliar a acurácia dos critérios de indicação da angiotomografia cervical no diagnóstico de LCCV em 100 doentes no trauma cervical contuso no Serviço de Trauma de hospital quaternário brasileiro. 
3 Material e Método 
Esta pesquisa foi aprovada pela Comissão de Ética para Análise de Projetos de Pesquisa - CAPPesq do Hospital das Clínicas da Faculdade de Medicina da Universidade de São Paulo. Trata-se de estudo baseado na coleta de dados de prontuários dos doentes vítimas de trauma contuso, admitidos no Pronto Socorro do Hospital das Clínicas da Faculdade de Medicina da Universidade de São Paulo (HCFMUSP), de julho de 2006 a dezembro de 2008 utilizando sinais clínicos e/ou radiográficos que possam representar potencial risco para LCCV. Estabeleceram-se onze critérios de inclusão no estudo, tendo como base os critérios mais frequentes utilizados em trabalhos existentes na literatura mundial.

Adotados os seguintes critérios de inclusão para realização da angiotomografia cervical: 1-défice neurológico unilateral não justificado pela tomografia computadorizada de crânio; 2-infarto cerebral identificado na tomografia computadorizada de crânio; 3-hematoma cervical não expansível; 4-epistaxe volumosa; 5-anisocoria/sinal de Horner; 6-escore menor do que 8 na escala de coma de Glasgow sem achados justificativos na tomografia computadorizada de crânio; 7-fratura de coluna cervical; 8-fratura de base de crânio; 9-fratura dos ossos da face com classificação de LeFort II e/ou III; 10 sinal do cinto de segurança acima da clavícula; 11-frêmito ou sopro cervical.

Os doentes foram submetidos à angiotomografia cervical se estivessem hemodinamicamente normais. Todas as angiotomografias foram realizadas no tomógrafo da marca GE, lightspeed ultra, helicoidal, multilice de 8 canais. Na Figura 1 está configurado anatômicamente o sítio das 
artérias caróticas e vertebrais e suas relações com a coluna cervical (Figura 1).

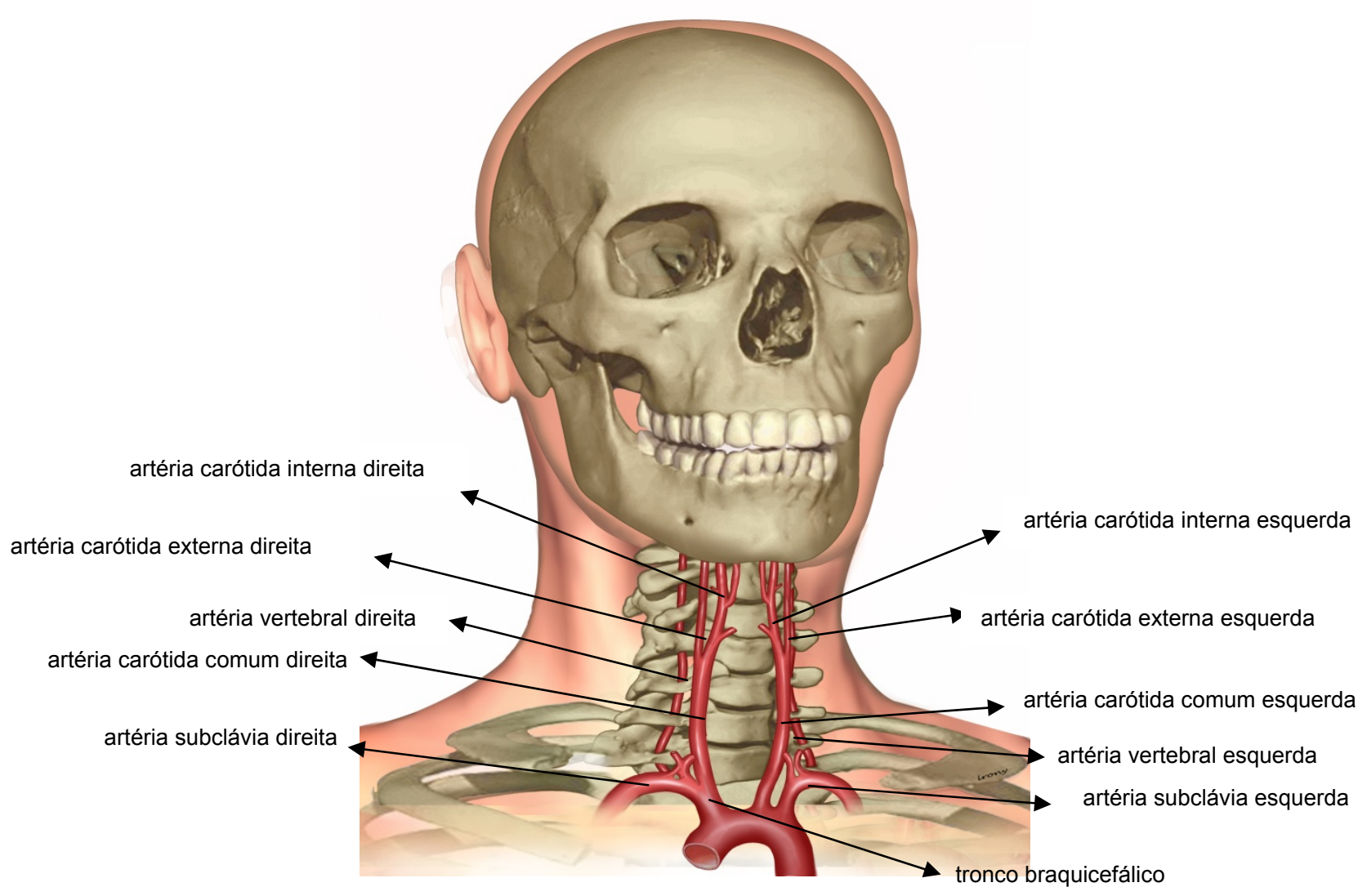

Figura 1 - Desenho de artérias carótidas e vertebrais e suas relações com a coluna cervical

Foram consideradas LCCV as seguintes alterações classificadas por graus de gravidade de um a cinco: 1-grau I as irregularidades da luz da artéria ou as dissecções com estenose inferior a 25\% da luz; 2-grau II as dissecções ou os hematomas intramurais com estenose igual ou maior do que $25 \%$ da luz, os trombos intraluminais ou as placas elevadas na íntima; 
3-grau III os pseudoaneurismas; 4-grau IV as oclusões, e 5-grau $V$ as secções com hemorragia. As fistulas foram classificadas separadamente.

A idade, o sexo, os mecanismos de trauma, os sinais vitais obtidos no atendimento inicial do doente traumatizado, bem como a frequência respiratória, a frequência cardíaca, a saturação arterial de $\mathrm{O}_{2}$, a pressão arterial e o escore na escala de coma de Glasgow foram analisadas. Foram, também calculados o RTS o ISS e a probabilidade de sobrevida calculada pela correlação entre o escore revisado de trauma, o escore de gravidade de lesão, o mecanismo de trauma e a idade do doente (TRISS).

Todos estes índices foram calculados na população de doentes sem lesões das artérias carótidas e vertebrais (Grupo I) e com lesões (Grupo II). Os dados são apresentados como média e desvio-padrão da média e as análises estatísticas foram realizadas com os testes de Qui-Quadrado e Exato de Fisher, e o teste de Mann-Whitney. Um nível de significância de 5\% ( $p$-valor $\leq 0,05)$ foi usado. 
4 Resultados

2 
No período de 30 meses do estudo, de julho de 2006 a dezembro de 2008, 2.467 doentes vítimas de trauma contuso foram internados no Serviço de Cirurgia de Emergência da III Divisão de Clínica Cirúrgica do Hospital das Clínicas da Faculdade de Medicina da Universidade de São Paulo. Desse total, 100 doentes apresentaram critérios para inclusão no estudo e foram submetidos à angiotomografia cervical. Do total de 100 doentes, 61 fizeram o exame logo após a avaliação clínica na sala de emergência e 39, após a estabilização hemodinâmica.

O tempo entre a admissão e a realização da angiotomografia cervical foi analisado e foi feita a comparação entre os Grupos I e II. Não houve diferença estatística significativa entre os Grupos I e II (Tabela 1)

Tabela 1 - Tempo entre a admissão e a realização da angiotomografia por Grupo

\begin{tabular}{lcccc}
\hline \multirow{2}{*}{ Tempo } & \multicolumn{2}{c}{ Grupo } & Total & p-valor \\
\cline { 2 - 4 } & Negativo & Positivo & & \\
\hline Imediato & $49(63,6 \%)$ & $12(52,2 \%)$ & $61(61 \%)$ & 0,3227 \\
Não imediato & $28(36,4 \%)$ & $11(47,8 \%)$ & $39(39 \%)$ & \\
\hline Total & 77 & 23 & 100 & \\
\hline
\end{tabular}

O tempo decorrido entre a admissão e a realização do exame variou de 1 até 18 dias. No grupo de 100 doentes, a angiotomografia identificou 77 doentes sem lesões de artérias carótidas e vertebrais (Grupo I) e 23 doentes com lesões dessas artérias (Grupo II). A incidência de lesões das artérias carótidas e vertebrais foi de $0,93 \%$ do total de doentes internados, com diagnóstico de trauma contuso, no período de 30 meses. A idade média da 
população total de 100 doentes foi de 34,81 anos com desvio-padrão de 14,84 e variação de 7 a 77 anos. No grupo de 77 doentes que não tinham lesões das artérias carótidas e vertebrais (Grupo I), a idade média foi de $35,43 \pm 15,49$ e no grupo dos 23 doentes com lesões (Grupo II) a média foi de $32,74 \pm 12,51$ anos.

Da população total de 100 doentes, 85 (85\%) eram do sexo masculino e $15(15 \%)$ do sexo feminino. Dos 85 doentes do sexo masculino, 68 não tinham lesões nas artérias carótidas e vertebrais (Grupo I) e 17 apresentavam (Grupo II). Dos 15 doentes do sexo feminino, nove não tinham lesões nas artérias carótidas e vertebrais (Grupo I) e seis tinham (Grupo II). Não houve diferença estatisticamente significativa entre os Grupos I e II no que se refere ao sexo e idade (Tabela 2).

Tabela 2 - Sexo e Idade de 100 doentes submetidos à angiotomografia cervical

\begin{tabular}{lcccc}
\hline & \multicolumn{2}{c}{ Grupos } & \multirow{2}{*}{ Total } & p-valor \\
\cline { 2 - 3 } & I (sem lesão) & II (com lesão) & & \\
\hline Sexo & & & & \\
F & $9(11,7 \%)$ & $6(26,1 \%)$ & $15(15 \%)$ & 0,1041 \\
M & $68(88,3 \%)$ & $17(73,9 \%)$ & $85(85 \%)$ & \\
\hline Idade & & & & \\
Média \pm DP & $35,43 \pm 15,49$ & $32,74 \pm 12,51$ & $34,81 \pm 14,84$ & 0,5147 \\
Mediana & 32 & 30 & 32 & \\
Mínimo-Máximo & $7-77$ & $15-56$ & $7-77$ & \\
\hline Total & 77 & 23 & 100 & \\
\hline
\end{tabular}

Os mecanismos de trauma da população total de 100 doentes foram: colisões de veículos motorizados (49 doentes); atropelamentos (24 doentes); 
agressões (4 doentes); queda de altura (18 doentes) e outros mecanismos (5 doentes). No grupo de 77 doentes sem lesões das artérias carótidas e vertebrais (Grupo I), a distribuição dos mecanismos de trauma foi a seguinte: colisões de veículos motorizados (36 doentes); atropelamentos (20 doentes); agressões (4 doentes); queda de altura (14 doentes); outros mecanismos (3 doentes).

No grupo dos 23 doentes portadores de lesões das artérias carótidas e vertebrais (Grupo II), a distribuição dos mecanismos de trauma foi a seguinte: colisões de veículos motorizados (13 doentes); atropelamentos (4 doentes); agressões (nenhum doente); queda de altura (4 doentes); outros mecanismos (2 doentes). Não houve diferença estatisticamente significativa entre os Grupos I e II no que se refere aos mecanismos de trauma (Tabela $3)$. 
Tabela 3 - Mecanismos de trauma em 100 doentes submetidos à angiotomografia cervical

\begin{tabular}{|c|c|c|c|c|}
\hline \multirow{2}{*}{ Mecanismo de trauma } & \multicolumn{2}{|c|}{ Grupos } & \multirow{2}{*}{ Total } & \multirow{2}{*}{ p-valor } \\
\hline & I (sem lesão) & II (com lesão) & & \\
\hline \multicolumn{5}{|c|}{ Colisão com veículos motorizados } \\
\hline Sim & $36(46,8 \%)$ & $13(56,5 \%)$ & $49(49 \%)$ & 0,4109 \\
\hline Não & $41(53,2 \%)$ & $10(43,5 \%)$ & $51(51 \%)$ & \\
\hline \multicolumn{5}{|l|}{ Atropelamento } \\
\hline Sim & $20(26 \%)$ & $4(17,4 \%)$ & $24(24 \%)$ & 0,3977 \\
\hline Não & $57(74 \%)$ & $19(82,6 \%)$ & $76(76 \%)$ & \\
\hline \multicolumn{5}{|l|}{ Agressões } \\
\hline Sim & $4(5,2 \%)$ & $0(0 \%)$ & $4(4 \%)$ & 0,5709 \\
\hline Não & $73(94,8 \%)$ & $23(100 \%)$ & $96(96 \%)$ & \\
\hline \multicolumn{5}{|l|}{ Quedas } \\
\hline $\operatorname{Sim}$ & $14(18,2 \%)$ & $4(17,4 \%)$ & $18(18 \%)$ & 1,0000 \\
\hline Não & $63(81,8 \%)$ & $19(82,6 \%)$ & $82(82 \%)$ & \\
\hline \multicolumn{5}{|l|}{ Outros mecanismos } \\
\hline Sim & $3(3,9 \%)$ & $2(8,7 \%)$ & $5(5 \%)$ & 0,3241 \\
\hline Não & $74(96,1 \%)$ & $21(91,3 \%)$ & 95 (95\%) & \\
\hline Total & 77 & 23 & 100 & \\
\hline
\end{tabular}

Os sinais vitais da população total de 100 doentes coletados durante o atendimento inicial na sala de emergência foram: pressão arterial sistólica de 123,09 \pm 22,93 mmHg, pressão arterial diastólica 77,91 \pm 19,94 mmHg, frequência respiratória de 15,82 \pm 11,05 irpm, frequência cardíaca de 98,91 $\pm 21,87$ bpm e a saturação de $93,23 \pm 7,94 \%$. Os doentes que não apresentaram lesões das artérias carótidas e vertebrais (Grupo I) tiveram 
uma pressão arterial sistólica com média de 123,35 $\pm 23,61 \mathrm{mmHg}$ e os que apresentaram lesão (Grupo II) tiveram uma média de 122,22 $\pm 20,96$ mmHg. Os doentes que não apresentaram lesões das carótidas e vertebrais (Grupo I) tiveram a pressão arterial diastólica com média de 79,16 $\pm 18,29 \mathrm{mmHg}$ e os que apresentaram lesões (Grupo II) tiveram uma média de 73,74 $\pm 24,69$ mmHg. Os doentes sem lesões das artérias carótidas e vertebrais (Grupo I) apresentaram uma frequência respiratória com média de 16,35 $\pm 12,88$ irpm e os que tiveram lesão (Grupo II), uma média de 14,04 \pm 3,96 irpm. Os doentes sem lesões das artérias carótidas e vertebrais (Grupo I) apresentaram uma frequência cardíaca com média de 97,92 $\pm 20,13$ bpm e os que tiveram lesões, uma média de 102,22 $\pm 27,17 \mathrm{bpm}$. Os doentes que não apresentaram lesões das artérias carótidas e vertebrais (Grupo I) tiveram uma saturação arterial com média de 93,08 \pm 8,17 mmHg e os que apresentaram lesões (Grupo II), uma média de 93,74 \pm 7,28 mmHg. Não houve diferença estatística significativa entre os Grupos I e II no que se refere à PAS, PAD, FR, FC, Saturação Arterial de $\mathrm{O}_{2}$ (Tabela 4). 
Tabela 4 - Sinais vitais em 100 doentes submetidos à angiotomografia cervical

\begin{tabular}{|c|c|c|c|c|}
\hline & \multicolumn{2}{|c|}{ Grupos } & \multirow{2}{*}{ Total } & \multirow{2}{*}{ p-valor } \\
\hline & I (sem lesão) & II (com lesão) & & \\
\hline \multicolumn{5}{|l|}{ PAS } \\
\hline Média \pm DP & $123,35 \pm 23,61$ & $122,22 \pm 20,96$ & $123,09 \pm 22,93$ & 0,6830 \\
\hline Mediana & 127 & 120 & 127 & \\
\hline Mínimo-Máximo & $60-165$ & $85-160$ & $60-165$ & \\
\hline \multicolumn{5}{|l|}{ PAD } \\
\hline Média \pm DP & $79,16 \pm 18,29$ & $73,74 \pm 24,69$ & $77,91 \pm 19,94$ & 0,1851 \\
\hline Mediana & 80 & 70 & 80 & \\
\hline Mínimo-Máximo & $30-120$ & $19,13-130$ & $19,13-130$ & \\
\hline \multicolumn{5}{|l|}{ FR } \\
\hline Média \pm DP & $16,35 \pm 12,38$ & $14,04 \pm 3,96$ & $15,82 \pm 11,05$ & 0,9606 \\
\hline Mediana & 14 & 15 & 15 & \\
\hline Mínimo-Máximo & $0-115$ & $5-20$ & $0-115$ & \\
\hline \multicolumn{5}{|l|}{ FC } \\
\hline Média \pm DP & $97,92 \pm 20,13$ & $102,22 \pm 27,17$ & $98,91 \pm 21,87$ & 0,2125 \\
\hline Mediana & 95 & 100 & 96 & \\
\hline Mínimo-Máximo & $45-145$ & $14-150$ & $14-150$ & \\
\hline \multicolumn{5}{|c|}{ Saturação Arterial de $\mathrm{O}_{2}$} \\
\hline Média \pm DP & $93,08 \pm 8,17$ & $93,74 \pm 7,28$ & $93,23 \pm 7,94$ & 0,7633 \\
\hline Mediana & 96 & 96 & 96 & \\
\hline Mínimo-Máximo & $50-100$ & $70-99$ & $50-100$ & \\
\hline Total & 77 & 23 & 100 & \\
\hline
\end{tabular}

PAS - Pressão Arterial Sistólica ;PAD - Pressão Arterial Diastólica ;FR - Frequência Respiratória ;FC - Frequência Cardíaca 
Os índices de trauma dos 100 doentes coletados na sala de emergência foram: escore na escala de coma de Glasgow 8,19 $\pm 3,96$, RTS $6,09 \pm 1,45$, ISS $25,97 \pm 16,15$, a probabilidade de sobrevida calculada pela correlação entre o escore revisado de trauma, o escore de gravidade de lesão, o mecanismo de trauma e a idade do doente (TRISS) $80,14 \pm 24,46$. Os doentes sem lesões das artérias carótidas e vertebrais (Grupo I) apresentaram um escore na escala de coma de Glasgow com média de 8,14 $\pm 4,02$ e os que tiveram lesões (Grupo II), uma média de $8,35 \pm 3,86$. Os doentes sem lesões das artérias carótidas e vertebrais (Grupo I) apresentaram um RTS com média de 6,10 \pm 1,45 e os que tiveram lesões (Grupo II), uma média de $6,05 \pm 1,45$. Os doentes que não tiveram lesões das artérias carótidas e vertebrais (Grupo I) apresentaram um ISS com média de $23,13 \pm 12,32$ e os que tiveram lesões (Grupo II) apresentaram uma média de $35,48 \pm 22,94$. Os doentes sem lesões das artérias carótidas e vertebrais (Grupo I) apresentaram a probabilidade de sobrevida calculada pela correlação entre o escore revisado de trauma, o escore de gravidade de lesão, o mecanismo de trauma e a idade do doente (TRISS) com média de $83,97 \% \pm 21,16 \%$ e os que tiveram lesões (Grupo II), uma média de $67,30 \%$ $\pm 30,34 \%$. Houve diferença estatisticamente significativa para o ISS e o TRISS entre os Grupos I e II (Tabela 5). 
Tabela 5 - Índice de gravidade em 100 doentes submetidos à angiotomografia cervical

\begin{tabular}{lcccc}
\hline & \multicolumn{2}{c}{ Grupos } & Total & p-valor \\
\cline { 2 - 3 } & I (sem lesão) & II (com lesão) & & \\
Média \pm DP & $8,14 \pm 4,02$ & $8,35 \pm 3,86$ & $8,19 \pm 3,96$ & 0,6818 \\
Mediana & 7 & 8 & 7 & \\
Mínimo-Máximo & $3-15$ & $3-15$ & $3-15$ & \\
Total & 77 & 23 & 100 & \\
\hline RTS & & & & 0,8205 \\
Média \pm DP & $6,1 \pm 1,45$ & $6,05 \pm 1,45$ & $6,09 \pm 1,45$ & \\
Mediana & 5,967 & 6 & 5,9835 & \\
Mínimo-Máximo & $3-8$ & $3,221-8$ & $3-8$ & \\
Total & 77 & 23 & 100 & \\
\hline ISS & & & & \\
Média \pm DP & $23,13 \pm 12,32$ & $35,48 \pm 22,94$ & $25,97 \pm 16,15$ & 0,0149 \\
Mediana & 22 & 27 & 22 & \\
Mínimo-Máximo & $6-75$ & $6-75$ & $6-75$ & \\
Total & 77 & 23 & 100 & \\
\hline TRISS & $3-100$ & $5-99$ & $3-100$ & \\
Média \pm DP & 77 & 23 & 100 & \\
Mediana & $94,97 \pm 21,16$ & $67,3 \pm 30,34$ & $80,14 \pm 24,46$ & 0,0235 \\
Mínimo-Máximo & 74 & 74 & 93 & \\
Total & & & & \\
\hline
\end{tabular}

GCS - Escore na escala de coma de Glasgow; RTS - Escore Revisado de Trauma; ISS Escore de Gravidade de Lesão; TRISS - Probabilidade de sobrevida calculada pela correlação entre o escore revisado de trauma, o escore de gravidade de lesão, o mecanismo de trauma e a idade do doente.

Os números de vezes que os critérios de inclusão estiveram presentes na população total de 100 doentes, foram: fratura dos ossos da face $44(44 \%)$ vezes, sendo LeFort II 14 (14\%) vezes, LeFort III 18 (18\%) vezes e ambos simultaneamente LeFort II e LeFort III 12 (12\%) vezes; fratura de vértebra cervical 37 (37\%) vezes; anisocorialSinal de Horner 24 (24\%) vezes; escore menor do que 8 na escala de coma de Glasgow sem 
achados justificativos na tomografia computadorizada de crânio 13 (13\%) vezes; fratura de base de crânio 14 (14\%) vezes; hematoma cervical não expansível $12(12 \%)$ vezes; epistaxe volumosa 9 (9\%) vezes; défice neurológico unilateral não justificado pela tomografia computadorizada de crânio 3 (3\%) vezes; infarto cerebral identificado na tomografia 4 (4\%) vezes; sinal do cinto de segurança acima da clavícula nenhuma vez e frêmito ou sopro na região cervical nenhuma vez. No Grupo de doentes que não apresentaram lesões das artérias carótidas e vertebrais, (Grupo I) os números de vezes que os critérios de inclusão estiveram presentes, foram os seguintes: fratura dos ossos da face $33(42,90 \%)$ vezes, sendo LeFort II $11(14,30 \%)$ vezes, LeFort III $14(18,20 \%)$ vezes e ambos simultaneamente LeFort II e LeFort III 8 (10,40\%) vezes; fratura de vértebra cervical 30 (39\%) vezes; anisocorialSinal de Horner $18(23,40 \%)$ vezes; escore menor do que 8 na escala de coma de Glasgow sem achados justificativos na tomografia computadorizada de crânio 11 (14,30\%) vezes; fratura de base de crânio 12 $(15,60 \%)$ vezes; hematoma cervical não expansível $11(14,30 \%)$ vezes; epistaxe volumosa $6(7,80 \%)$ vezes; défice neurológico unilateral não justificado pela tomografia computadorizada de crânio $3(3,90 \%)$ vezes; infarto cerebral identificado na tomografia $2(2,60 \%)$ vezes; sinal do cinto de segurança acima da clavícula nenhuma vez e frêmito ou sopro na região cervical nenhuma vez. No Grupo de doentes que apresentaram lesões das artérias carótidas e vertebrais, (Grupo II) os números de vezes que os critérios de inclusão estiveram presentes, foram os seguintes: fratura dos ossos da face $11(47,80 \%)$ vezes, sendo LeFort II 3 (13\%) vezes, LeFort III 4 
$(17,40 \%)$ vezes e ambos simultaneamente LeFort II e LeFort III $4(17,40 \%)$ vezes; fratura de vértebra cervical $7(30,40 \%)$ vezes; anisocorialSinal de Horner $6(26,10 \%)$ vezes; escore menor do que 8 na escala de coma de Glasgow sem achados justificativos na tomografia computadorizada de crânio 2 (8,70\%) vezes; fratura de base de crânio 2 (8,70\%) vezes; hematoma cervical não expansível 1 (4,30\%) vez; epistaxe volumosa 3 (13\%) vezes; déficit neurológico unilateral não justificado pela tomografia computadorizada de crânio nenhuma vez; infarto cerebral identificado na tomografia $2(8,70 \%)$ vezes; sinal do cinto de segurança acima da clavícula nenhuma vez e frêmito ou sopro na região cervical nenhuma vez (Tabela 6). 
Tabela 6 - Número de vezes do aparecimento de critérios de inclusão no estudo em 100 doentes submetidos à angiotomografia cervical

\begin{tabular}{|c|c|c|c|c|}
\hline & \multicolumn{2}{|c|}{ Grupo } & \multirow{2}{*}{ Total } & \multirow{2}{*}{ p-valor } \\
\hline & I (sem lesão) & II (com lesão) & & \\
\hline \multicolumn{5}{|c|}{ Fratura dos ossos da face } \\
\hline $\operatorname{Sim}$ & $33(42,90 \%)$ & $11(47,80 \%)$ & $44(44 \%)$ & 0,6736 \\
\hline Não & $44(57,10 \%)$ & $12(52,20 \%)$ & $56(56 \%)$ & \\
\hline \multicolumn{5}{|c|}{ Fratura de vértebra cervical } \\
\hline $\operatorname{Sim}$ & $30(39 \%)$ & $7(30,40 \%)$ & $37(37 \%)$ & 0,6233 \\
\hline Não & $47(61 \%)$ & $16(69,60 \%)$ & $63(63 \%)$ & \\
\hline \multicolumn{5}{|c|}{ Anisocoria/Sinal de Horner } \\
\hline Sim & $18(23,40 \%)$ & $6(26,10 \%)$ & $24(24 \%)$ & 0,7858 \\
\hline Não & $59(76,60 \%)$ & $17(73,90 \%)$ & $76(76 \%)$ & \\
\hline \multicolumn{5}{|c|}{ GCS $<8$ sem achados na TC de crânio } \\
\hline $\operatorname{Sim}$ & $11(14,30 \%)$ & $2(8,70 \%)$ & $13(13 \%)$ & 0,7268 \\
\hline Não & $66(85,70 \%)$ & $21(91,30 \%)$ & $87(87 \%)$ & \\
\hline \multicolumn{5}{|c|}{ Fratura de base de crânio } \\
\hline $\operatorname{Sim}$ & $12(15,60 \%)$ & $2(8,70 \%)$ & $14(14 \%)$ & 0,5124 \\
\hline Não & $65(84,40 \%)$ & $21(91,30 \%)$ & $86(86 \%)$ & \\
\hline \multicolumn{5}{|l|}{ Hematoma cervical } \\
\hline Sim & $11(14,30 \%)$ & $1(4,30 \%)$ & $12(12 \%)$ & 0,2864 \\
\hline Não & $66(85,70 \%)$ & $22(95,70 \%)$ & $88(88 \%)$ & \\
\hline \multicolumn{5}{|l|}{ Epistaxe volumosa } \\
\hline Sim & $6(7,80 \%)$ & $3(13 \%)$ & $9(9 \%)$ & 0,4257 \\
\hline Não & $71(92,20 \%)$ & $20(87 \%)$ & $91(91 \%)$ & \\
\hline \multicolumn{5}{|c|}{ Défice neurológico unilateral não justificado pela TC de crânio } \\
\hline $\operatorname{Sim}$ & $3(3,90 \%)$ & $0(0 \%)$ & $3(3 \%)$ & - \\
\hline Não & $74(96,10 \%)$ & $23(100 \%)$ & $97(97 \%)$ & \\
\hline \multicolumn{5}{|c|}{ Infarto cerebral identificado na TC de crânio } \\
\hline Sim & $2(2,60 \%)$ & $2(8,70 \%)$ & $4(4 \%)$ & 0,2258 \\
\hline Não & $75(97,40 \%)$ & $21(91,30 \%)$ & $96(96 \%)$ & \\
\hline \multicolumn{5}{|c|}{ Sinal do cinto de segurança acima da clavícula } \\
\hline Sim & $0(0 \%)$ & $0(0 \%)$ & $0(0 \%)$ & - \\
\hline Não & $77(100 \%)$ & $23(100 \%)$ & $100(100 \%)$ & \\
\hline \multicolumn{5}{|c|}{ Frêmito ou sopro na região cervical } \\
\hline Sim & $0(0 \%)$ & $0(0 \%)$ & $0(0 \%)$ & - \\
\hline Não & $77(100 \%)$ & $23(100 \%)$ & $100(100 \%)$ & \\
\hline Total de doentes & 77 & 23 & 100 & \\
\hline
\end{tabular}

TC - Tomografia computadorizada; GCS - Escore na escala de coma de Glasgow 
O estudo estatístico foi realizado correlacionando os critérios de inclusão por grupo na população total de 100 doentes comparando os Grupos I e II. Não houve diferença estatística significativa entre os Grupos I e II. (Tabela 7).

Tabela 7 - Critérios de inclusão por Grupo em 100 doentes submetidos à angiotomografia cervical

\begin{tabular}{rcccc}
\hline \multirow{2}{*}{ Critérios } & \multicolumn{2}{c}{ Grupo } & Total & p-valor \\
\cline { 2 - 4 } & Negativo & Positivo & & \\
\hline 1 & $40(51,9 \%)$ & $12(52,2 \%)$ & $52(52 \%)$ & 0,9997 \\
2 & $27(35,1 \%)$ & $8(34,8 \%)$ & $35(35 \%)$ & \\
3 & $10(13 \%)$ & $3(13 \%)$ & $13(13 \%)$ & \\
\hline Total & 77 & 23 & 100 & \\
\hline
\end{tabular}

As lesões de outros seguimentos corpóreos que não a região cervical, encontram-se descritas na Tabela 8, discriminadas como o número de vezes de ocorrência na população total de 100 doentes e nos grupos sem lesões das artérias carótidas e vertebrais (Grupo I), e com lesões das artérias carótidas e vertebrais (Grupo II).

Tabela 8 - Outras lesões encontradas fora da região cervical em 100 doentes submetidos à angiotomografia cervical

\begin{tabular}{|c|c|c|c|}
\hline \multirow[b]{2}{*}{ Lesões } & \multirow{2}{*}{$\begin{array}{c}\text { N de vezes de } \\
\text { ocorrência da } \\
\text { lesão em } \\
\text { população de } 100 \\
\text { doentes }\end{array}$} & \multicolumn{2}{|c|}{ Doentes } \\
\hline & & Grupo I & Grupo II \\
\hline Hemorragia subdural & 20 & 16 & 4 \\
\hline Hemorragia extradural & 20 & 14 & 4 \\
\hline Hemorragia subaracnóide & 24 & 18 & 4 \\
\hline Hemorragia meningeia traumática & 8 & 7 & 1 \\
\hline Lesão axonial difusa & 10 & 9 & 1 \\
\hline
\end{tabular}




\begin{tabular}{|c|c|c|c|}
\hline Traumatismo raquimedular & 2 & 2 & - \\
\hline Infarto cerebral & 1 & 0 & 1 \\
\hline Trauma ocular & 3 & 1 & 2 \\
\hline Pneumotórax & 8 & 4 & 4 \\
\hline Trauma de traqueia & 1 & 1 & - \\
\hline Fratura osso hióide & 1 & 1 & - \\
\hline Hemotórax & 9 & 6 & 3 \\
\hline Derrame pleural & 3 & 1 & 2 \\
\hline Contusão pulmonar & 12 & 10 & 2 \\
\hline Fratura de costela & 12 & 10 & 2 \\
\hline Tórax instável & 3 & 3 & - \\
\hline Atelectasia & 1 & 1 & - \\
\hline Trauma hepático & 15 & 11 & 4 \\
\hline Trauma de pâncreas & 1 & - & 0 \\
\hline Trauma de intestino delgado & 1 & 1 & 0 \\
\hline Insuficiência renal aguda (contraste) & 2 & 2 & - \\
\hline Trauma renal & 4 & 3 & 1 \\
\hline Trauma esplênico & 6 & 5 & 1 \\
\hline Trauma gland. Adrenal & 1 & - & 1 \\
\hline Fratura fechada de membro superior & 11 & 7 & 4 \\
\hline Fratura aberta de membro superior & 2 & 2 & - \\
\hline Fratura de escápula & 8 & 4 & 4 \\
\hline Fratura de clavícula & 9 & 8 & 1 \\
\hline Lesão de plexo braquial & 1 & - & 1 \\
\hline Fratura de esterno & 2 & 2 & - \\
\hline Fratura de bacia & 9 & 7 & 2 \\
\hline Fratura de ilíaco & 3 & 3 & - \\
\hline Luxação de quadril & 1 & 1 & - \\
\hline Fratura aberta do fêmur & 1 & 1 & - \\
\hline Fratura fechada do fêmur & 4 & 2 & 2 \\
\hline Fratura aberta dos ossos da perna & 10 & 7 & 3 \\
\hline Fratura fechada dos ossos da perna & 6 & 4 & 2 \\
\hline Fratura de patela & 2 & 1 & 1 \\
\hline Fratura processo articular T1 & 1 & - & 1 \\
\hline Fratura T1 & 4 & 4 & - \\
\hline Fratura do processo transverso de $\mathrm{T} 1$ & 1 & 1 & - \\
\hline Fratura L4 & 1 & 1 & - \\
\hline Fratura processo transverso L5 & 1 & 1 & - \\
\hline Secção art. Subclávia & 2 & 1 & 1 \\
\hline Trombose seio transverso dirt./ sigmóide dirt. & 1 & 1 & - \\
\hline
\end{tabular}




\begin{tabular}{llll}
\hline Lesão art. Meningeia & 1 & - & 1 \\
Lesão art. Espinhal & 1 & - & 1 \\
Lesão art. occipital/maxilar/facial & 1 & - & 1 \\
Fratura T12 & 1 & 1 & - \\
Fratura processo transverso T2 & 1 & 1 & - \\
Fratura T1 T2 T4 T9 T10 T11 & 1 & 1 & - \\
Fratura T12 & 1 & 1 & - \\
Fratura processo transverso L1 L2 L3 & 1 & 1 & - \\
Fratura L1 & 1 & 1 & - \\
Fratura L3 & 1 & 1 & - \\
Fratura processo transverso L5 & 1 & - & 1 \\
TVP & 1 & 1 & - \\
\hline
\end{tabular}

Grupo I: sem lesões das artérias carótidas e vertebrais Grupo II: com lesões das artérias carótidas e vertebrais 
Nos 23 doentes do Grupo II identificaram-se na angiotomografia 12 lesões das artérias carótidas: 1 lesão (8,33\%) da artéria carótida comum esquerda; 1 lesão (8,33\%) da artéria carótida comum direita; 6 lesões $(49,93 \%)$ da artéria carótida interna direita e 4 lesões $(33,33 \%)$ da artéria carótida interna esquerda. Onze doentes tiveram lesões das artérias vertebrais: 8 (72,7\%) do lado esquerdo; e em 2 destes tinham concomitância de lesões da artéria subclávia; e 3 do lado direito $(27,2 \%)$ (Tabela 9).

Nenhum doente apresentou lesão de carótida e vertebral juntas. Quatro doentes apresentaram lesões vasculares fora da topografia da região cervical: 1 doente com lesão da artéria meningeia; 1 doente com lesão das artérias occipital, maxilar e facial; 1 doente com trombose do seio transverso direito e seio sigmóide direito e 1 doente com pseudoaneurisma da artéria espinhal.

Tabela 9 - Lesões das artérias carótidas e vertebrais no Grupo II n=23 doentes

\begin{tabular}{lll}
\hline & Carótida comum E & 1 \\
Carótidas -12 & Carótida comum D & 1 \\
& Carótida interna D & 6 \\
& Carótida interna E & 4 \\
\hline Vertebrais -11 & Esquerda & 8 \\
& Direita & 3 \\
\hline
\end{tabular}


A distribuição dos 23 doentes portadores de LCCV, conforme o grau de lesão foi a seguinte: lesões grau I 7 doentes, grau II 10 doentes, grau IV 4 doentes, grau $\mathrm{V} 1$ doente, e uma fístula de carótida (Tabela 10).

Tabela 10 - Graus das lesões das artérias carótidas e vertebrais em 23 doentes do Grupo II

\begin{tabular}{|c|c|c|c|}
\hline Graus Artérias & Artérias vertebrais & Artérias carótidas & Total \\
\hline Grau I & 4 & 3 & 7 \\
\hline Grau II & 5 & 5 & 10 \\
\hline Grau III & - & - & - \\
\hline Grau IV & 2 & 2 & 4 \\
\hline Grau V & - & 1 & 1 \\
\hline Trombose & - & - & - \\
\hline Fístula & - & 1 & 1 \\
\hline Totais & 11 & 12 & 23 \\
\hline
\end{tabular}

O tratamento dos 23 doentes que apresentaram lesões das artérias carótidas e vertebrais foi o seguinte: 15 doentes foram submetidos a anticoagulação com heparina (e dois, desses 15 doentes, foram, também, submetidos à cirurgia aberta somente para correção da lesão da artéria subclávia), dois doentes foram apenas observados e seis doentes foram tratados com técnica endovascular, um doente com colocação de stent e cinco por embolização com gelfoam. 
No grupo de 77 doentes que não apresentaram lesões das artérias carótidas e vertebrais, $14(18,1 \%)$ morreram e 63 (81,8\%) sobreviveram. Dos 63 sobreviventes, $16(25,3 \%)$ apresentaram sequelas do trauma e $6(9,52 \%)$, complicações. As sequelas do trauma em 16 doentes do grupo I foram as seguintes: 2 parestesia, 2 tetraplegias, 5 paresias e 7 hemiplegias. As complicações nos 6 doentes do grupo I foram as seguintes: 1 insuficiência respiratória, 1 instabilidade hemodinâmica, 1 sepse, 1 trombosa venosa profunda, 1 insuficiência renal aguda e 1 falência de múltiplos órgãos.

Dos 23 doentes do grupo II que apresentaram lesões das artérias carótidas e vertebrais $7(30,4 \%)$ faleceram e $16(69,5 \%)$ sobreviveram. Dos 16 sobreviventes, 10 apresentaram sequelas: uma lesão do plexo braquial, uma parestesia, três tetraplegias, cinco paresias. Um doente apresentou complicação durante a internação, trombose venosa profunda.

A mortalidade dos 100 doentes do estudo foi de $21(21 \%)$ doentes. Comparando-se a mortalidade do Grupo I com a do Grupo II, não houve diferença estatisticamente significativa entre elas (Tabela 11).

Tabela 11 - Comparação entre as mortalidades do Grupo I e do Grupo II

\begin{tabular}{ccccc}
\hline \multirow{2}{*}{ Óbito } & \multicolumn{2}{c}{ Grupo } & \multirow{2}{*}{ Total } & p-valor \\
\cline { 2 - 3 } & I (sem lesão) & II (com lesão) & & \\
\hline Não & $63(81,8 \%)$ & $16(69,6 \%)$ & $79(79 \%)$ & 0,2457 \\
Sim & $14(18,2 \%)$ & $7(30,4 \%)$ & $21(21 \%)$ & \\
\hline Total & 77 & 23 & 100 & \\
\hline
\end{tabular}


Comparando-se o TRISS entre o grupo de 79 doentes que sobreviveram e o grupo de 21 doentes que morreram, observamos uma diferença estatisticamente significativa (Tabela 12).

Tabela 12 - Comparação das probabilidades de sobrevida pelo TRISS entre os Grupos de doentes que sobreviveram (79) e que morreram (21) dos 100 doentes do estudo

\begin{tabular}{|c|c|c|c|c|}
\hline \multirow{2}{*}{ TRISS } & \multicolumn{2}{|c|}{ Óbito } & \multirow{2}{*}{ Total } & \multirow{2}{*}{ p-valor } \\
\hline & Não & Sim & & \\
\hline Média \pm DP & $85,13 \pm 19,66$ & $61,38 \pm 31,4$ & $80,14 \pm 24,46$ & $\underline{0,0004}$ \\
\hline Mediana & 94 & 72 & 93 & \\
\hline Mínimo - Máximo & $9-100$ & $3-99$ & $3-100$ & \\
\hline Total & 79 & 21 & 100 & \\
\hline
\end{tabular}

Comparando-se a porcentagem de sobrevida dos Grupos I e II com suas respectivas probabilidades de sobrevida calculadas pelo escore TRISS, não encontramos diferenças estatisticamente significativas (Tabela 13).

Tabela 13 - Comparação entre o percentual real de sobreviventes com o percentual de sobrevida calculada pelo TRISS

\begin{tabular}{lcccccc}
\hline Grupo & $\mathbf{N}$ & $\begin{array}{c}\text { Óbito } \\
\text { real }\end{array}$ & $\begin{array}{c}\text { Sobrevida } \\
\text { real }\end{array}$ & $\begin{array}{c}\text { Probabilidade de } \\
\text { sobrevida } \\
\text { (média TRISS) }\end{array}$ & $\mathbf{Z}$ & p-valor \\
\hline $\begin{array}{l}\text { Sem lesões de carótidas } \\
\text { e vertebrais }\end{array}$ & 77 & $18,18 \%$ & $81,82 \%$ & $83,97 \%$ & 0,34 & 0,7318 \\
$\begin{array}{l}\text { Com lesões de carótidas } \\
\text { e vertebrais }\end{array}$ & 23 & $30,43 \%$ & $69,57 \%$ & $67,30 \%$ & 0,01 & 0,9928 \\
\hline
\end{tabular}


5 Discussão 
Inicialmente, é importante fazer algumas considerações sobre os mecanismos de trauma para que se tenha uma compreensão melhor das lesões das artérias carótidas e vertebrais. Em 1974, Crissey e Bernstein ao iniciarem a investigação das lesões das artérias carótidas e vertebrais, identificaram quatro tipos fundamentais de mecanismos de trauma correlacionados com as lesões ${ }^{(7)}$. Tipo I (Figura 2) é resultado de trauma contuso fechado abaixo do pescoço (cinto de segurança, estrangulamento e enforcamento). Tipo II é o mais comum, que resulta do movimento do chicote, fratura e luxação da vértebra cervical e da hiperextensão rotação contralateral da cabeça e pescoço (Figuras 3, 4, 5). Tais lesões justificam-se pela relação anatômica dos processos articulares laterais e pedículos das três primeiras vértebras cervicais que se projetam mais anteriormente do que as quatro vértebras inferiores. Portanto, haverá um estiramento em toda a superfície da parede da artéria carótida interna durante a hiperextensão cervical ${ }^{(8)}$. $\mathrm{Na}$ rotação da articulação atlantoaxial, pode haver movimentação anterior das vértebras produzindo uma lesão por estiramento. Lesões tipo III são produzidas por trauma de face (Figuras 6,7,8), podendo ser encontradas, também, em crianças que caem com objeto rígido na boca, como por exemplo, uma escova de dente. Tipo IV são lesões associadas com fraturas da base do crânio envolvendo o osso esfenóide ou petroso, resultando em laceração das artérias vertebrais ou carótidas internas ${ }^{(9)}$ (Figuras 7,8, 9,10). 


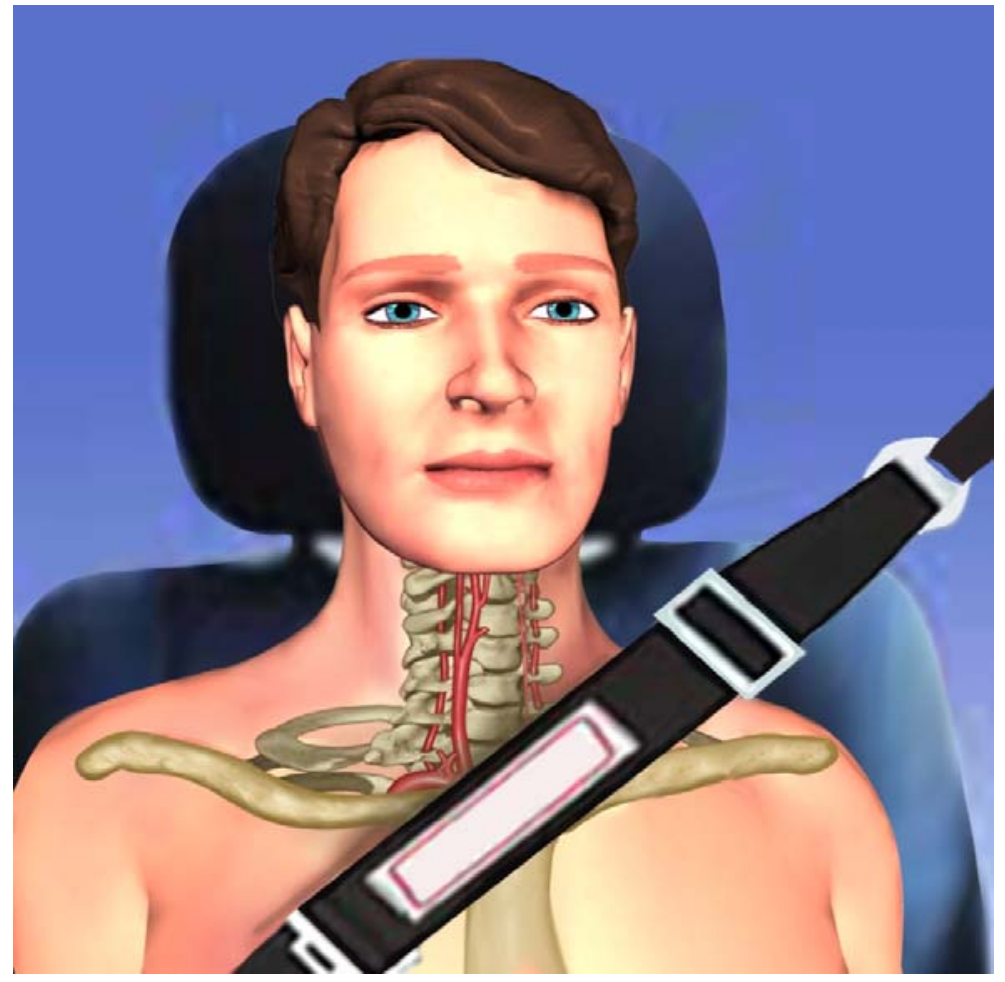

Figura 2 - Desenho de trauma contuso por cinto de segurança em região cervical

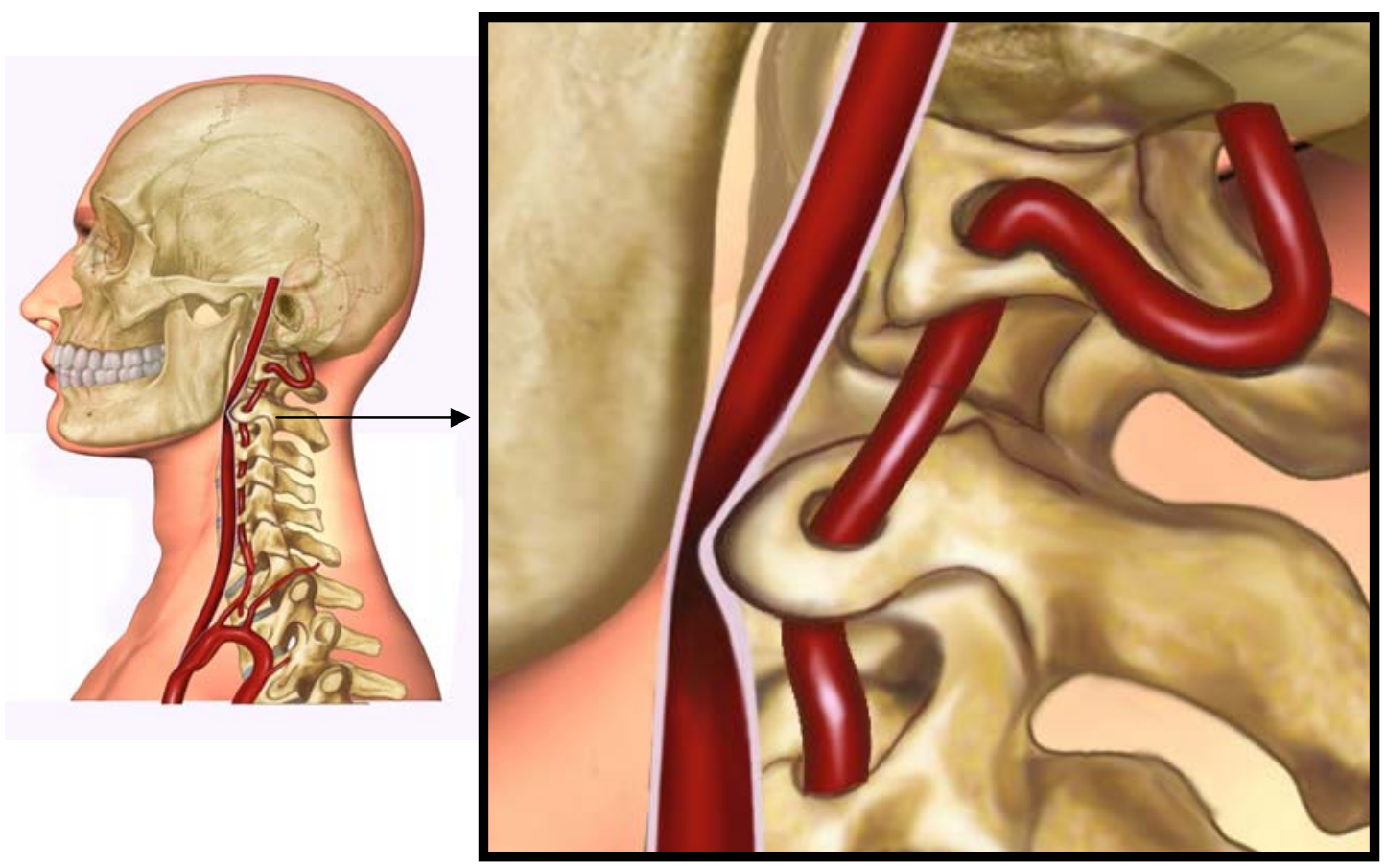

Figura 3 - Desenho de subluxação de $C_{3}$ comprimindo a artéria carótida interna esquerda 

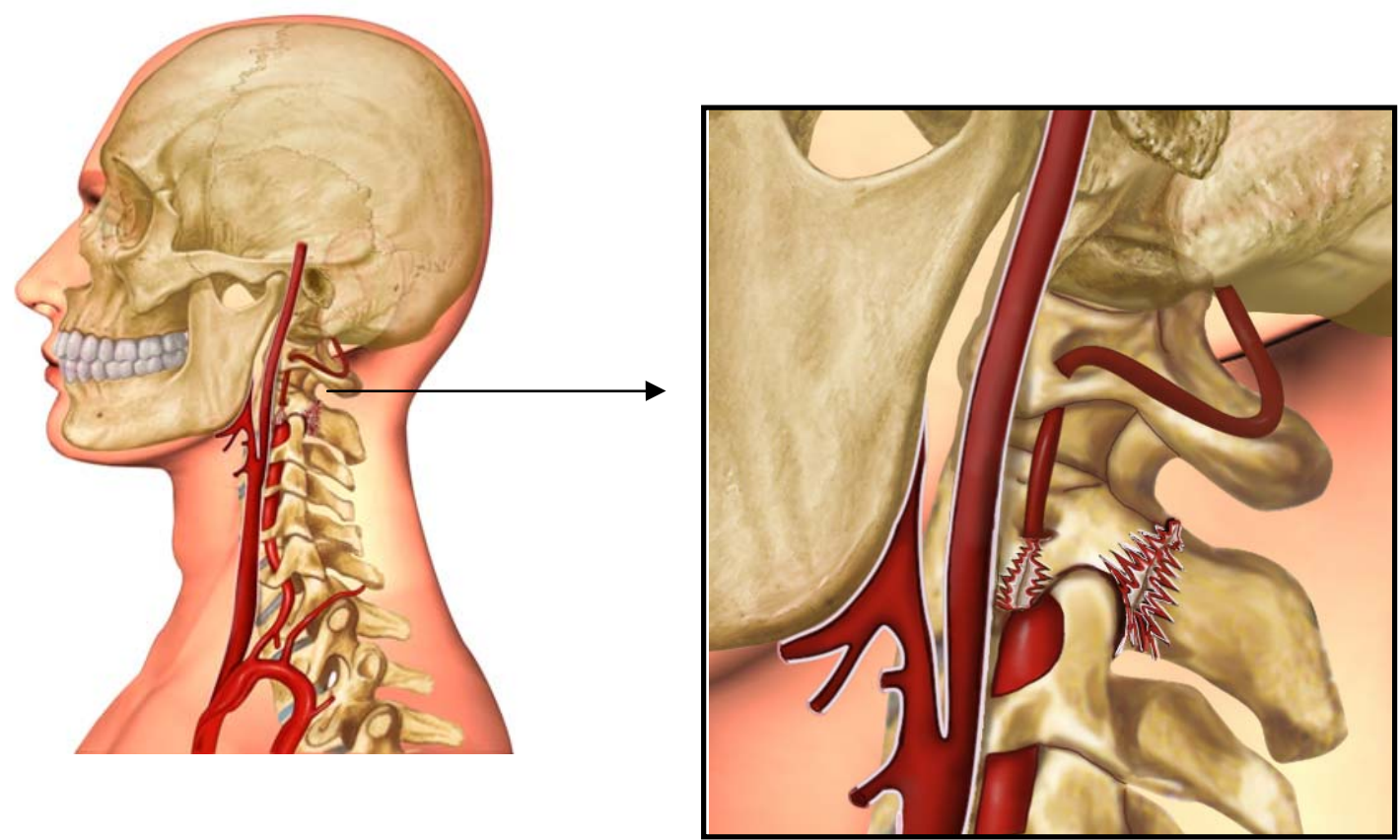

Figura 4 - Desenho de fratura do processo espinhoso e forame transverso comprimindo a artéria vertebral esquerda

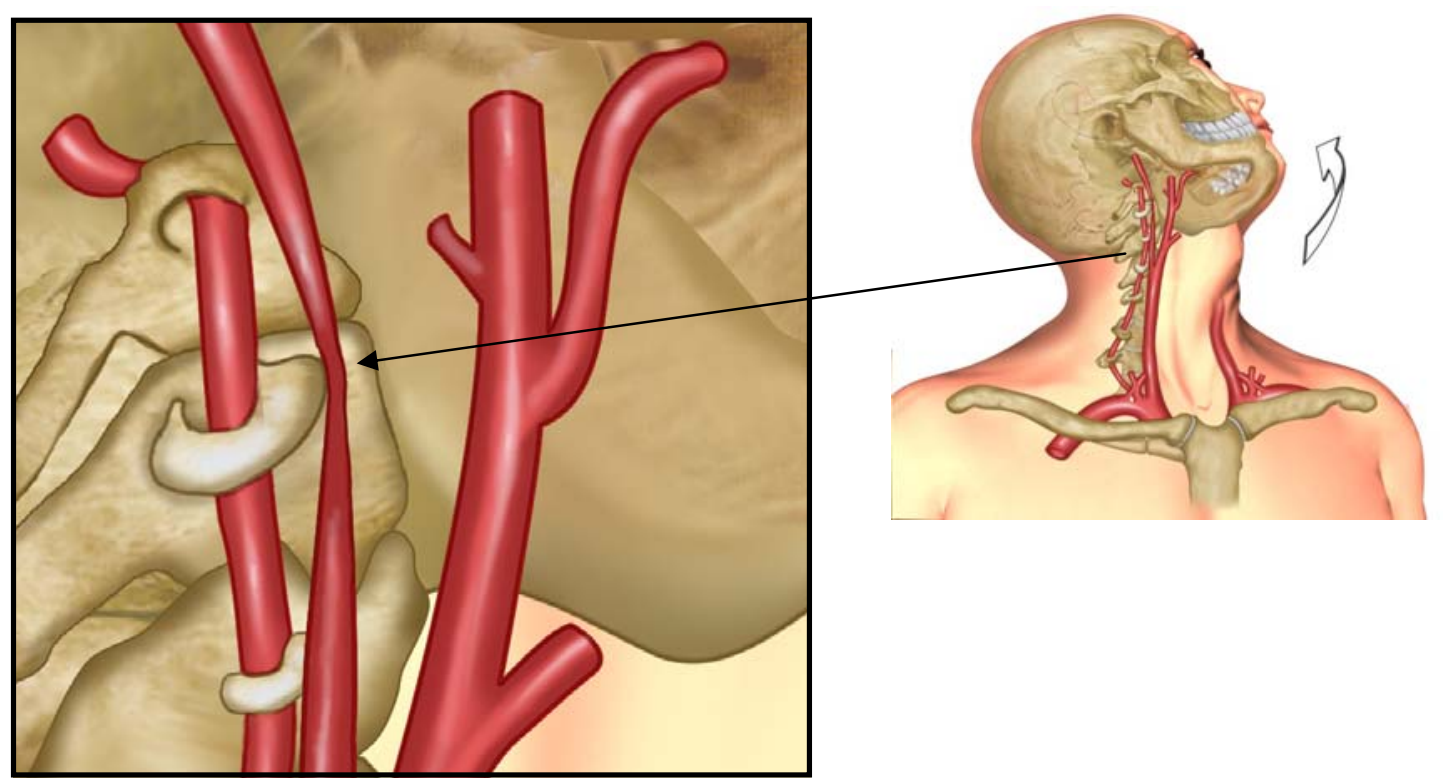

Figura 5 - Desenho de hiperextensão e flexão do pescoço comprimindo a artéria carótida interna direita 

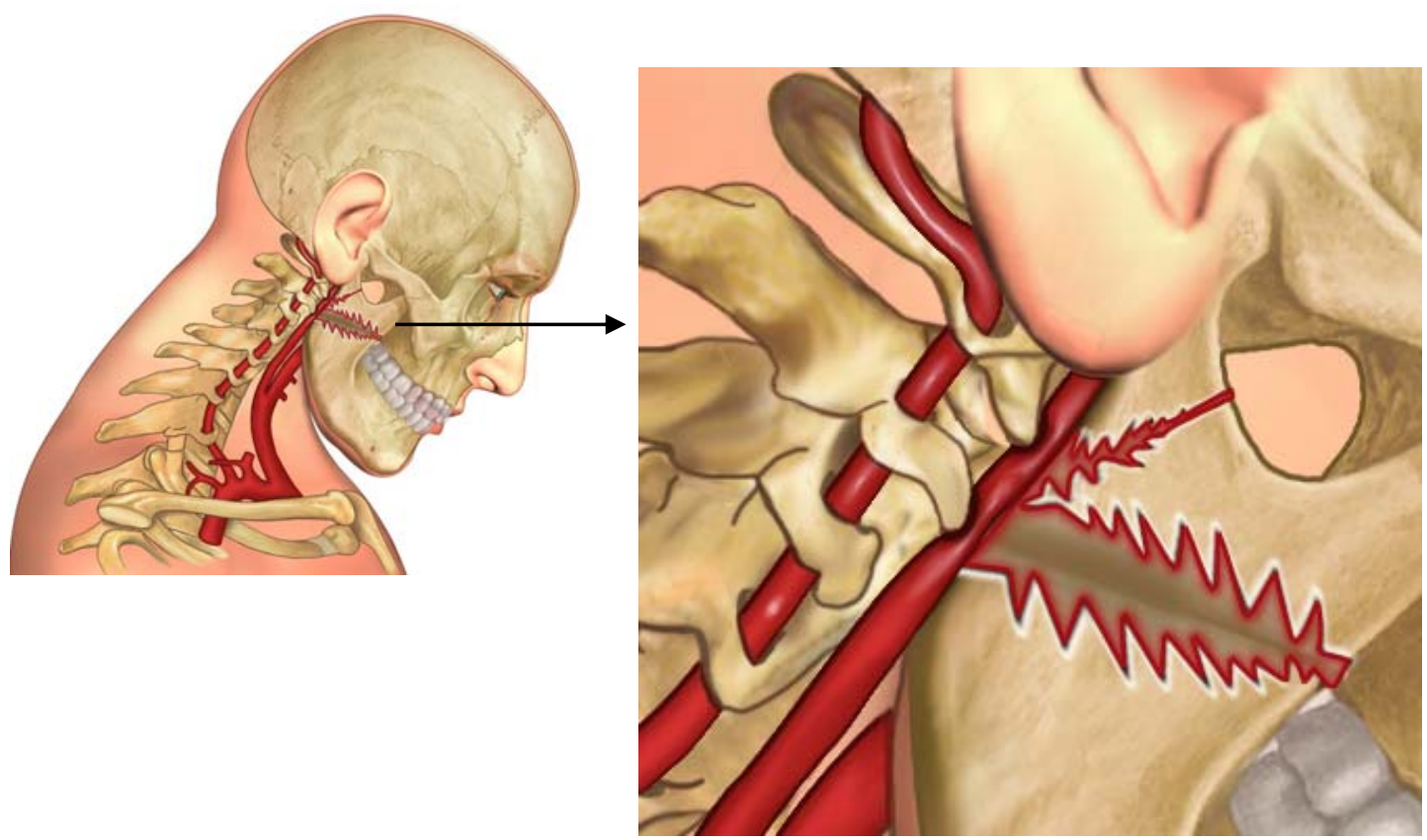

Figura 6 - Desenho de fratura de mandíbula comprimindo a artéria carótida interna direita
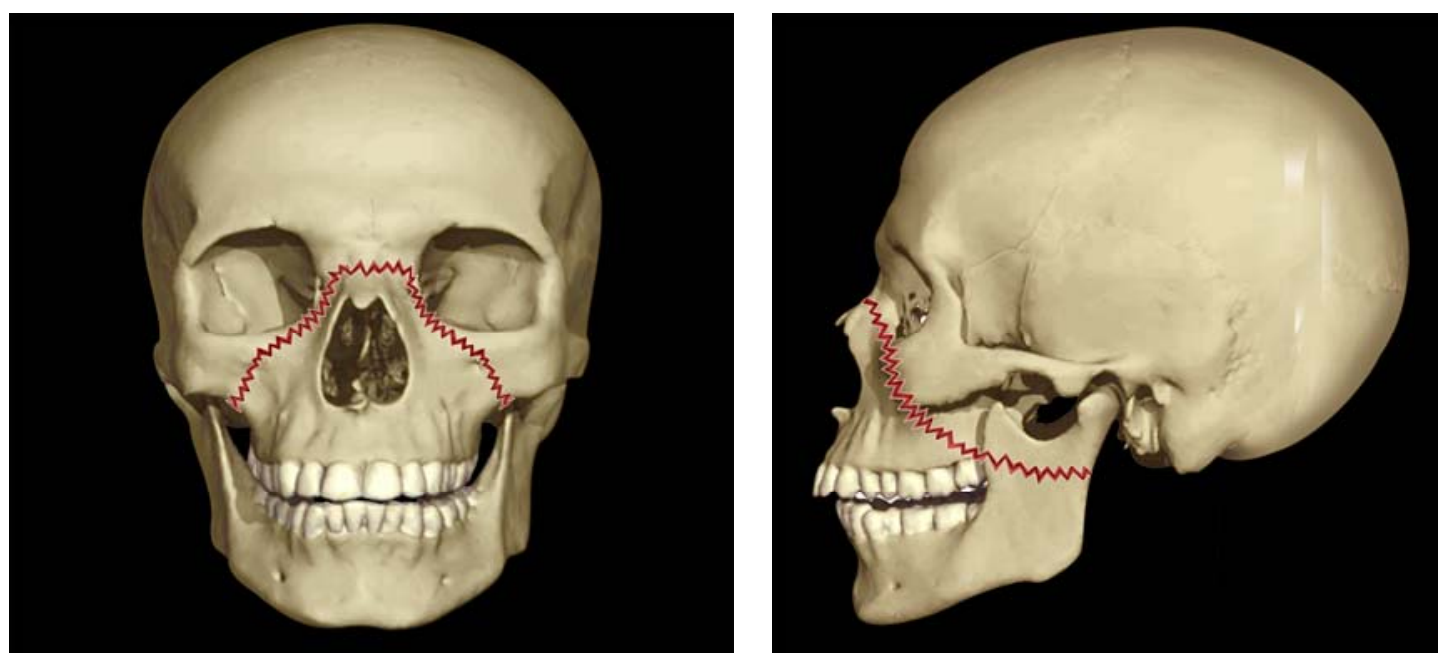

Figura 7 - Desenho de fratura de face tipo LeFort II 

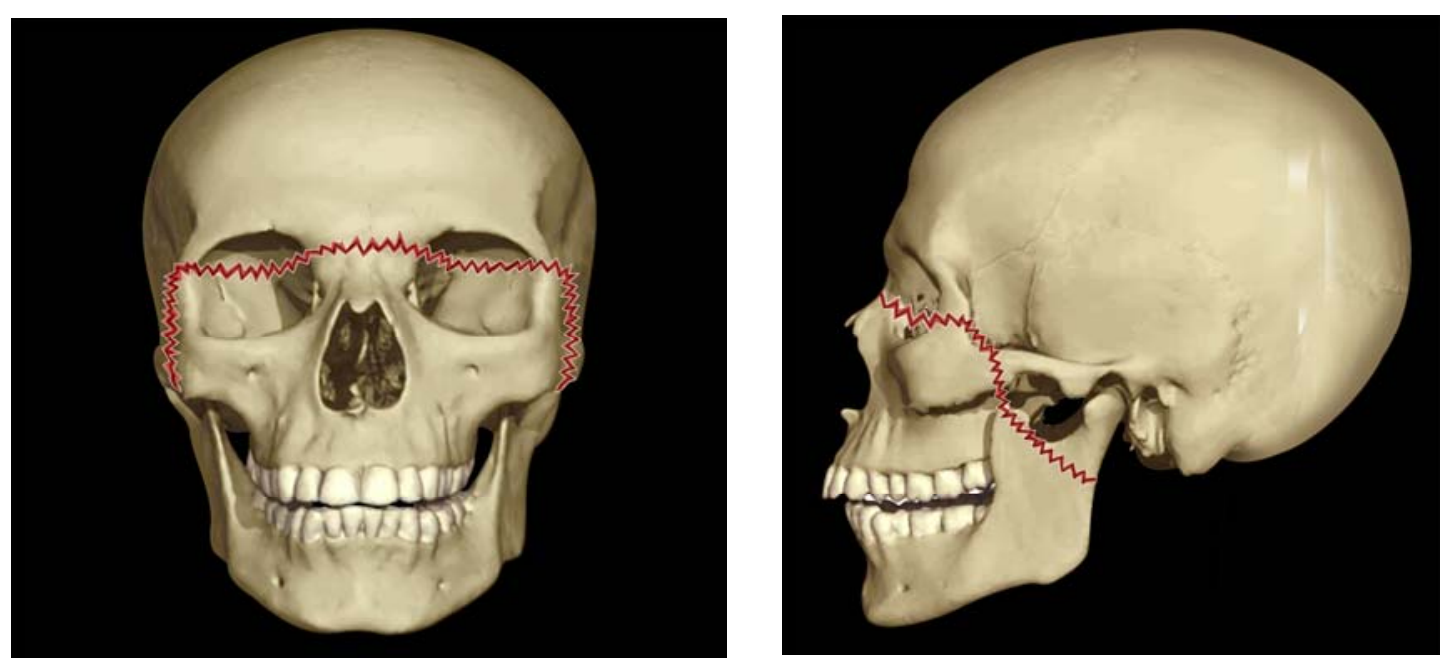

Figura 8 - Desenho de fratura de face tipo LeFort III 


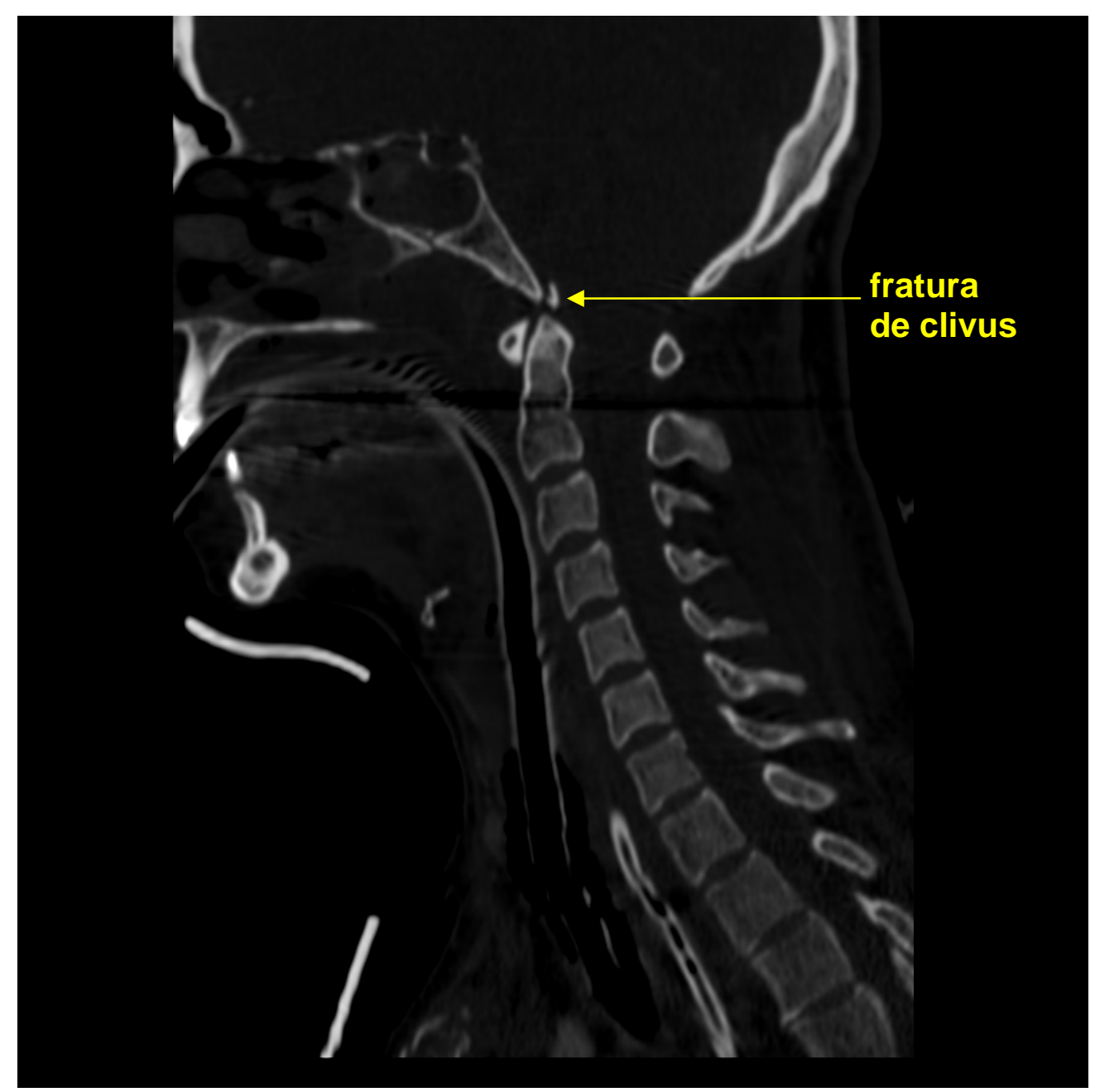

Figura 9 - Tomografia de transição crânio-cervical: fratura de base de crânio (clivus) 
$\mathrm{Na}$ literatura médica, inúmeros casos já foram relatados documentando mecanismos de trauma que na realidade não são valorizados para se suspeitar de LCCV. Na verdade, são considerados traumas corriqueiros ou triviais como os que ocorrem em quiropraxia, atletismo, cabeleireiro, chaqualhando uma criança, no balançar da cabeça do roqueiro, a virada rápida do pescoço, o ato de tossir, o vomitar e o barbear ${ }^{(10)}$.

Ao se analisar todos os artigos científicos, fica esclarecido que essas lesões são passiveis de ocorrer, podendo causar subitamente evento cerebral predominantemente isquêmico. Por falta de conhecimento dos fatores etiológicos causadores das dissecções arteriais, ocasionando isquemia cerebral, a taxa populacional de acometidos pode alcançar $2,5 \%{ }^{(1)}$.

Desse modo, é fato que existem patologias responsáveis por causarem dissecções espontâneas como crise hipertensiva, síndrome de Marfan, displasia fibromuscular, sífilis, arteriopatias e necrose da túnica média cística de Erdheim. A ausência de trauma não elimina a possibilidade do doente ser portador de lesão vascular em região cervical. Em nosso estudo de cem doentes, verificamos que os mecanismos mais comuns em ordem decrescente de incidência foram: colisões de veículos motorizados (carros, motos, ônibus e caminhões), atropelamentos, quedas e agressões. Nestes tipos de trauma, consideramos que deve ocorrer hiperextensão e rotação, levando ao estiramento bem como compressão e lesão direta das artérias e fraturas cervicais. 
No que diz respeito à fisiopatologia das lesões, deve-se considerar que qualquer que seja o mecanismo de trauma, em muitos casos, ocorre rotura da camada interna da parede arterial, promovendo a trombogênese, acúmulo de plaquetas que podem levar à embolização ou formação de hematoma na parede do vaso, causando compressão extrínseca e oclusão da luz da artéria (Figura 10).

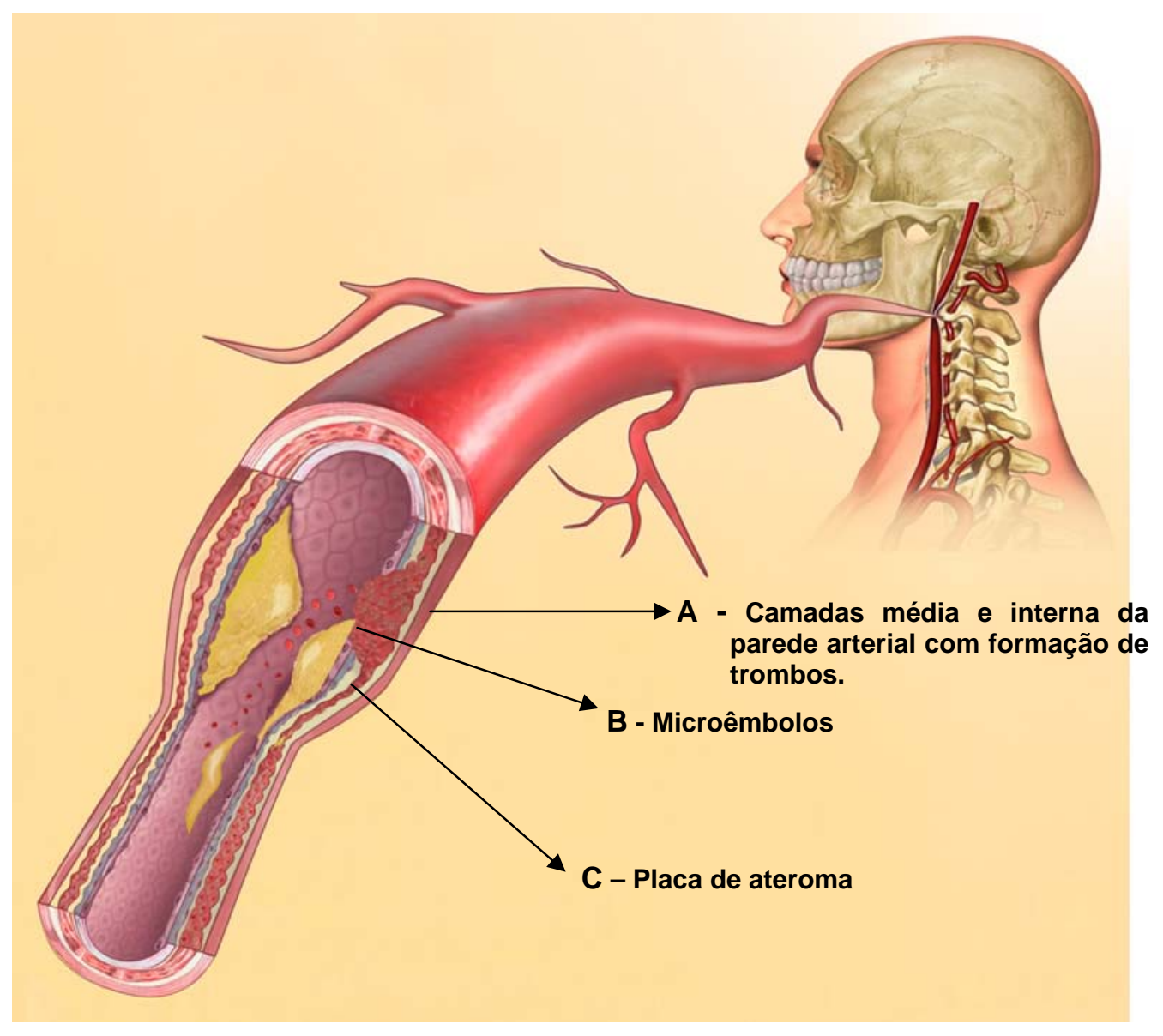

Figura 10 - Representação esquemática de lesão da parede da artéria carótida interna após contusão cervical causando embolizações. 
A dissecção também pode ocasionar um sangramento progressivo e compressão do vaso com estreitamento luminar e subsequente oclusão do vaso. Menos comum é a transecção parcial ou total da artéria com formação do falso aneurisma e posterior rotura, causando hemorragia intra ou extracraniana ou formação de fístula arteriovenosa. A manifestação clínica neurológica e sua magnitude dependem do tipo de lesão (vertebral e/ou carótida) a complexidade da lesão vascular e a existência ou não da circulação colateral. Identificamos nos 23 doentes portadores de lesões das artérias carótidas e vertebrais a ocorrência de dissecções com estenoses inferiores a $25 \%$ de sua luz em sete doentes, dissecções ou hematomas com estenoses iguais ou maiores do que $25 \%$ da sua luz em dez doentes, oclusões em quatro doentes, dissecções com hemorragia em um doente e fístula em um doente.

Em relação ao quadro clínico do doente neurológico, há sinais e sintomas que estão associados à lesão de vaso arterial que podem sugerir a presença de lesão cerebrovascular por trauma, antes de um ataque isquêmico cerebral. Dores no pescoço, no ouvido, na face ou periorbital, concomitante ou não com hemorragia e dissecção da parede arterial, podem ser sintomas comuns presentes em até $60 \%$ dos doentes ${ }^{(11)}$. De modo geral, a dor é um sintoma que poderá ser atribuível a diversas lesões presentes em uma vítima de trauma em vários seguimentos corpóreos ou, especificamente, no pescoço e/ou cabeça, porém, deve-se lembrar da existência de LCCV, também. A síndrome de Horner pode resultar da rotura do plexo simpático periarterial, 
lembrando que a assimetria pupilar pode ter várias etiologias. Entretanto, se a pupila de maior tamanho estiver reativa e a de menor não estiver, deve se suspeitar de lesão arterial cervical ${ }^{(12)}$.

O exame neurológico sistemático contribui para identificar a isquemia cerebral, porém, nenhum exame propedêutico isolado é suficiente para efetuar o diagnóstico preciso da lesão mas sim a propedêutica armada com exame de imagem que identifica tanto a lesão arterial como sua extensão. Os sinais e/ou sintomas de isquemia cerebral podem estar ausentes na LCCV aguda.

Conforme já comentado nos mecanismos de trauma, tanto a origem como as consequências das lesões dessas 4 artérias, estão mais voltadas para os problemas provocados pela obstrução e isquemia resultante e não tanto pelos episódios de sangramento. O sangramento talvez represente algum problema, quando o doente apresentar hematoma cervical ou epistaxe volumosa. Todos os outros sinais e sintomas encontram-se muito mais relacionados aos problemas advindos da isquemia. Por outro lado, a dor é um sintoma comum que pode ter múltiplas origens, desde um ferimento na região do trauma até uma dissecção arterial como prenúncio de uma possível lesão cérebro vascular.

Na população de 100 doentes desse estudo, é importante salientar que a grande maioria apresentava traumatismo de vários seguimentos corpóreos, com dores difusas, o que pode ser comprovado pelo ISS médio de quase, 26, caracterizando doentes muito graves. Ainda, 44 doentes apresentavam fraturas dos ossos da face o que também é origem de dor. Por outro lado, do 
total de 100 doentes, 24 apresentavam anisocoria/sinal de Horner; 12, hematoma cervical; epistaxe, porém, apenas, quatro apresentavam infarto cerebral identificado na TC de crânio. Dessa forma, a dor, os sinais de sangramento e o sinal de Horner, realmente, devem ser valorizados.

Não se tem determinada a real incidência da LCCV por trauma contuso, sobretudo por ser uma doença aparentemente infrequente e pouco investigada. Existem poucos estudos na literatura e ainda não se determinou o conjunto de informações que definam a causa exata da LCCV. No entanto, as estatísticas mais recentes demonstram que não é incomum quando a LCCV é sistematicamente investigada em doentes assintomáticos ${ }^{(2,10,11,12)}$.

Estudos multicêntricos realizados nos anos 1990, identificaram uma incidência de $0,08 \%$ a $0,17 \%$ de LCCV nos hospitais especializados no atendimento ao traumatizado ${ }^{(2,6,11,12)}$. Em outros serviços, a incidência foi maior variando de $0,24 \%$ a $0,50 \%{ }^{(3,4)}$. Hoje há serviços que já alcançaram taxas de até $1,0 \%{ }^{(13)}$. Autores argumentam que a incidência tem aumentado, por ser feita uma triagem mais específica nos doentes com trauma de crânio e pescoço assintomáticos, sem isquemia cerebral, o que possibilita efetuar o diagnóstico. Em nosso estudo, a incidência de LCCV em doentes assintomáticos foi de $0,93 \%$, admitidos nos 30 meses analisados.

Embora muitos serviços especializados em trauma tenham elaborado protocolos para identificar pacientes com LCCV, há um consenso geral de que fatores de risco sempre estarão presentes ao selecionar os doentes candidatos à LCCV. 
Pesquisadores como Fabian et col, realizaram estudo retrospectivo no decorrer de 11 anos, analisando doentes portadores de lesões das artérias carótidas resultantes de trauma fechado e identificaram alguns fatores de risco que poderiam ser usados em estudos futuros para identificar precocemente doentes portadores de LCCV, antes que evoluíssem para isquemia cerebral (3). O doente poderia ter um ou mais critérios de risco para LCCV. Entretanto, Biffl et col ${ }^{(14)}$, durante 2 anos e meio, selecionaram doentes assintomáticos com a utilização de sete critérios de risco para lesões dos vasos cervicais e observaram um aumento da incidência de LCCV que era de $0,1 \%$ para $1,1 \%$.

De fato, o emprego de critérios para identificar potenciais portadores de LCCV, deve, naturalmente, aumentar a incidência de diagnóstico das lesões dos vasos cervicais; por outro lado, o uso de métodos diagnósticos por imagem mais específicos, menos ou não invasivos, como angiotomografia ou angiorressonância, fatalmente elevarão o custo do atendimento ao traumatizado. De forma ideal, deveriam ser encontrados os critérios mais frequentes e um número limitado de critérios para triagem e, assim, aprimorar o diagnóstico sem aumento exagerado de custo.

No presente estudo, foram escolhidos 11 critérios de inclusão para identificar traumatizados portadores de LCCV. Todos estes critérios reúnem sinais e sintomas clínicos, bem como alterações identificadas em radiografias simples. A intenção foi verificar dentre os vários critérios relatados em trabalhos anteriores, se havia alguns critérios que fossem mais significativos para escolha da melhor triagem possível. Infelizmente, não se conseguiu 
mostrar nenhum critério que fosse predominante em relação aos outros quando comparados os grupos sem e com LCCV.

Realizamos estudos para avaliar o número de critérios para LCCV que cada doente poderia ter e a relação desses em cada grupo. Identificamos que nos 23 doentes com LCCV não houve uma relação significativa entre o número de critérios para LCCV e a ocorrência de LCCV (Tabela 7). Talvez em casuísticas maiores seja possível dizer que a utilização de vários critérios não é necessária. Acreditamos que todos os 11 critérios devam ser utilizados para se identificar LCCV no traumatizado, vítima de trauma contuso em nosso meio (Tabela 6).

Biffl et col estudaram o problema das LCCV durante um período bem maior de 9 anos ${ }^{(1,10,11)}$. Um dos objetivos era de identificar critérios de risco associados ou independentes que pudessem causar LCCV. Por meio de uma análise multivariada dos critérios que usaram, identificaram que o escore menor ou igual a 6 na escala de coma de Glasgow, a fratura do osso petroso, a lesão axonial difusa e as fraturas de face tipo LeFort II ou III foram critérios que se correlacionaram de maneira significativa com as lesões das artérias carótidas por trauma contuso. A fratura de vértebra cervical foi identificada como o único critério de risco preditivo e independente para lesão das artérias vertebrais no trauma contuso. Em nosso meio, até o momento e na literatura de nosso conhecimento, não existem estudos que consigam definir a incidência de LCCV e os critérios de risco que mais se correlacionam com elas. Neste estudo, identificamos que a incidência de LCCV foi de $0,93 \%$ na população de doentes traumatizados por trauma contuso e não conseguimos 
mostrar a predominância significativa de um critério de risco sobre os demais estudados.

Alguns autores estudando especificamente os fatores de risco para as lesões das artérias vertebrais argumentam que, nem todos os doentes portadores de qualquer tipo de fratura de coluna cervical, mas apenas aqueles que apresentam subluxação, fraturas que se estendem até o forame transverso e fraturas de vértebras de C1 a C3 deveriam ser estudadas em triagens sistematizadas nos serviços de trauma ${ }^{(15)}$.

No que se refere aos parâmetros vitais, frequência cardíaca, pressão arterial, frequência respiratória e saturação arterial de oxigênio identificados durante o atendimento inicial do traumatizado na sala de emergência, a literatura não relata diferenças entre os doentes portadores de lesões de artérias carótidas e vertebrais e aqueles que não apresentam essas lesões. 0 fato talvez seja por que estamos estudando uma população de doentes, vítimas de trauma contuso. Outro ponto que merece consideração, é que a investigação diagnóstica dessas quatro artérias requer a realização de exames prolongados, como angiotomografia e arteriografia, que, normalmente, não são realizados em doentes hemodinamicamente instáveis, mas apenas em doentes hemodinamicamente estáveis. Neste estudo, comparando todos esses parâmetros de sinais vitais entre os grupos com e sem lesões das artérias carótidas e vertebrais, não encontramos diferenças significativas. 
Os índices de trauma são usados rotineiramente para classificar a gravidade dos traumatizados. Alguns autores relatam gravidade maior no grupo de doentes portadores de lesões das artérias carótidas e vertebrais. Esta diferença de gravidade é mais evidente nos índices anatômicos como o ISS ${ }^{(11)}$. Em relação aos índices fisiológicos como o RTS e a escala de coma de Glasgow, não se observam relatos de diferenças importantes entre os doentes que apresentam ou não lesões dessas artérias. Os doentes que apresentam critérios para investigação de lesões de artérias cervicais, geralmente, não mostram repercussões hemodinâmicas importantes, mas apresentam traumatismos cranioencefálicos e cervicais importantes.

Assim, geralmente, apresentam um RTS não muito alterado e um GCS bastante alterado. Neste estudo, o GCS dos 100 doentes foi quase 8 , sem diferença entre os grupos com e sem lesões das artérias carótidas e vertebrais. O RTS médio da população de 100 doentes foi, aproximadamente, 6, sem diferença significativa entre os Grupos I e II.

Por outro lado, o ISS médio da população de 100 doentes foi, aproximadamente, 26 com médias de 23 para o grupo de doentes sem lesões de artérias carótidas e vertebrais e 35,5 para o grupo de doentes com lesões dessas artérias. Houve diferença significativa entre os Grupos I e II com gravidade maior para o Grupo II. Consequentemente, esse mesmo comportamento foi observado em relação à probabilidade de sobrevida observada pelo TRISS. A probabilidade de sobrevida foi menor (67\%) no Grupo II do que no Grupo I (84\%), com uma probabilidade média de sobrevida para a população de 100 doentes de $80 \%$ (Tabela 5). De fato, a mortalidade 
do Grupo total de 100 doentes foi de $21 \%$ com uma mortalidade de $18 \%$ para o Grupo I e 30,5\% para o Grupo II. A comparação entre o percentual de sobreviventes com o percentual de sobrevida calculada pelo TRISS não revelou diferença significativa (Tabela 13).

O método de imagem considerado como "padrão ouro" na maioria dos trabalhos da literatura que estuda vasos cervicais é a arteriografia. Sem dúvida nenhuma, este exame tem seu papel muito bem estabelecido há muito tempo. Mas, vários aspectos importantes devem ser considerados no tratamento do doente traumatizado. A grande maioria dos atendimentos de trauma ocorre em horários e dias fora da rotina normal de trabalho, assim, a utilização da arteriografia em um cenário de um centro de trauma não é isenta de limitações.

Observa-se também, que nem todos os serviços de trauma possuem um setor de diagnóstico por arteriografia funcionando 24 horas por dia e 7 dias por semana. Outros aspectos que devem ser considerados na realização da arteriografia, são os seguintes: é um exame altamente invasivo, que apresenta complicações clínicas, como: alergia, choque anafilático, insuficiência renal, bem como complicações cirúrgicas, tais como o pseudoaneurisma e o hematoma no local da punção.

Não há exame alternativo não invasivo com alta sensibilidade, para fazer diagnóstico em doentes assintomáticos. Serviços radiológicos experientes em estudo de vasos cervicais já consideram o Duplex ultrassonográfico uma alternativa, porém, com limitações: $86 \%$ de 
sensibilidade, dificuldade de identificar lesão arterial na base do crânio e evidências indiretas não fidedignas de distúrbio do fluxo arterial com estenoses menores do que $60 \%{ }^{(12,18,19)}$.

A angiorressonância magnética apresenta $50 \%$ de sensibilidade para identificação das lesões da carótida e $47 \%$ para identificação das lesões da artéria vertebral ${ }^{(16)}$. É um exame não invasivo e com potencial de sensibilidade crescente. Tem capacidade de estudar simultaneamente vasos cervicais e circulação cerebral. No entanto, é um exame caro e disponível apenas em poucos hospitais. Outro grande problema da angiorressonância é ser bastante demorado, portanto, raramente realizado no atendimento inicial dos doentes traumatizados.

A angiotomografia tem sido, frequentemente, utilizada em vários trabalhos que estudam o problema das lesões das artérias carótidas e vertebrais. Parece ter uma boa acurácia na identificação das estenoses e das dissecções das artérias carótidas. Dois grupos já documentaram sensibilidade de $90 \%$ a $100 \%$ e especificidade de $100 \%$ para a angiotomografia na identificação de lesões arteriais cervicais originadas por ferimentos penetrantes ${ }^{(17,18)}$. Por outro lado, Miller et col. alegam que, a angiotomografia empregada no doente, vítima de trauma contuso, tem sensibilidade de $47 \%$ para detectar lesão da artéria carótida e 53\% para identificar a lesão da artéria vertebral (16). Outros autores como Roger et col. empregaram a angiotomografia, como uma modalidade útil para a triagem de doentes com suspeita de lesões de artérias carótidas e vertebrais ${ }^{(19)}$. Biffl et col. acreditam que a angiotomografia sendo efetuada em tomógrafo tipo multislice de 16 
canais pode apresentar imagens com resolução significativa, fidedigna com excelente acurácia com poucos falsos negativos. Outros tomógrafos com mais canais, provavelmente, irão mostrar lesões que não seriam identificadas em aparelhos convencionais. Talvez haja dificuldade em se justificar o uso da arteriografia em doentes assintomáticos, pois é um exame que está cada vez mais se aperfeiçoando na qualidade das imagens com o aprimoramento da tecnologia ${ }^{(11)}$.

Existem vários aspectos da angiotomografia que Ihe conferem um papel muito atraente, como ferramenta para o estudo das LCCV, sobretudo em doentes assintomáticos. O aspecto mais importante é que a grande maioria dos doentes que apresentam indicações para o estudo das artérias cervicais, já possui indicações de realização de tomografia para investigação de outros seguimentos corpóreos.

Assim, o doente não necessitaria de um encaminhamento adicional para o serviço de diagnóstico somente para estudar os vasos cervicais. 0 estudo das artérias carótidas e vertebrais pela angiotomografia seria, então, realizado com o estudo de outras lesões, como as cerebrais, as fraturas da face ou da base do crânio, bem como lesões de outras estruturas da região cervical, como por exemplo, a coluna vertebral.

Em nosso estudo, todos os 100 doentes foram submetidos à angiotomografia cervical pelo tomógrafo tipo multislice de 8 canais e nenhuma anormalidade referente às imagens foi identificada, demonstrando confiança na resolução das mesmas. As lesões das artérias carótidas e vertebrais foram 
detectadas em 23 (23\%) doentes. Dos 23 que fizeram angiotomografia, 6 (26\%) realizaram arteriografia para realização de procedimentos terapêuticos (Cinco embolizações e uma colocação de stent). Um doente dos 77 que não apresentaram lesões das artérias carótidas e vertebrais evoluiu com insuficiência renal aguda, pelo uso do contraste, mas recuperou-se, ficando sem sequelas permanentes posteriormente.

A ocorrência das lesões das artérias carótidas e vertebrais no trauma contuso é bastante variada quando se analisam os trabalhos da literatura. $O$ maior problema é que a grande maioria dos trabalhos apresenta estudos separados das artérias carótidas e das artérias vertebrais. Poucos trabalhos relatam investigações que pesquisaram as lesões das quatro artérias simultaneamente. Um bom exemplo é o trabalho de Miller et col., que realizou arteriografia em 216 doentes com critérios de risco para lesões de artérias cervicais, durante um período de 2 anos e identificou $24(11,11 \%)$ doentes com lesões de artérias carótidas contra 43 (19,71\%) doentes com lesões de artérias vertebrais ${ }^{(16)}$.

Outro trabalho foi realizado por McKinney et col. Que, no período de 13 meses, fez arteriografia em 71 doentes com critérios de risco para lesões das artérias cervicais. Assim, identificou 12 doentes com lesões das artérias carótidas e 12, com lesões das artérias vertebrais ${ }^{(20)}$.

No presente trabalho, dos 100 doentes com critérios de risco para lesões das artérias carótidas e vertebrais, encontramos 12 com lesões das artérias carótidas e 11 com lesões das artérias vertebrais. Os resultados deste 
trabalho são bastante semelhantes aos de McKinney, apenas com uma incidência um pouco menor no presente trabalho.

Conforme já apresentado na metodologia, foi usada a classificação das lesões das artérias carótidas e vertebrais que variam de grau I a V. Esta classificação separa as lesões sem significância hemodinâmica (Grau I) daquelas com potencial significância hemodinâmica (Grau II), Figura 11, os pseudoaneurismas (Grau III) Figura 11, as oclusões (Grau IV) Figura 12 e as transecções dos vasos (Grau V) Figuras 13 e 14. 


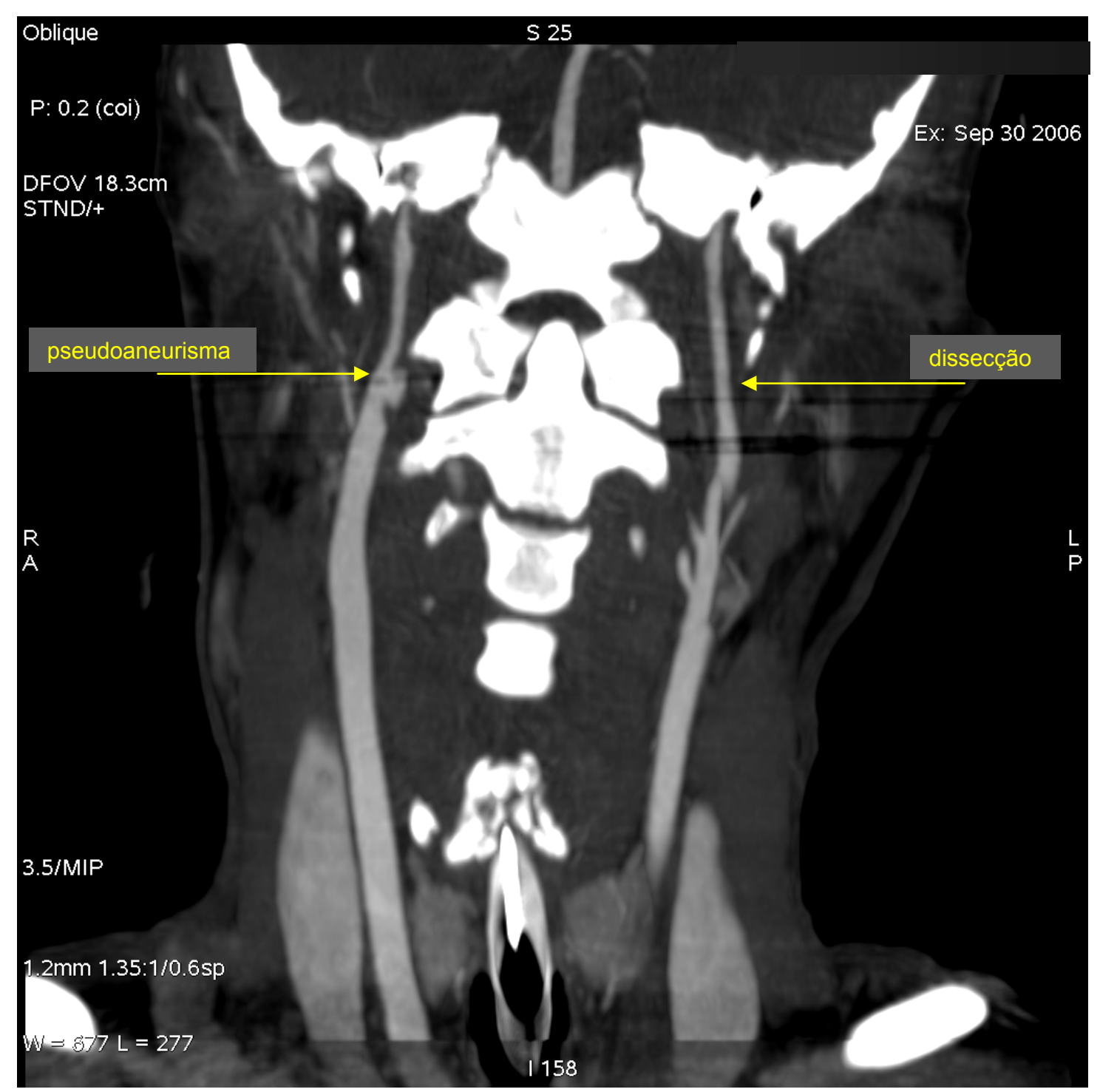

Figura 11A Angiotomografia dos vasos cervicais identificando pseudoaneurisma na artéria carótida interna direita (grau III) e dissecção maior que $25 \%$ da artéria carótida esquerda (grau II) 


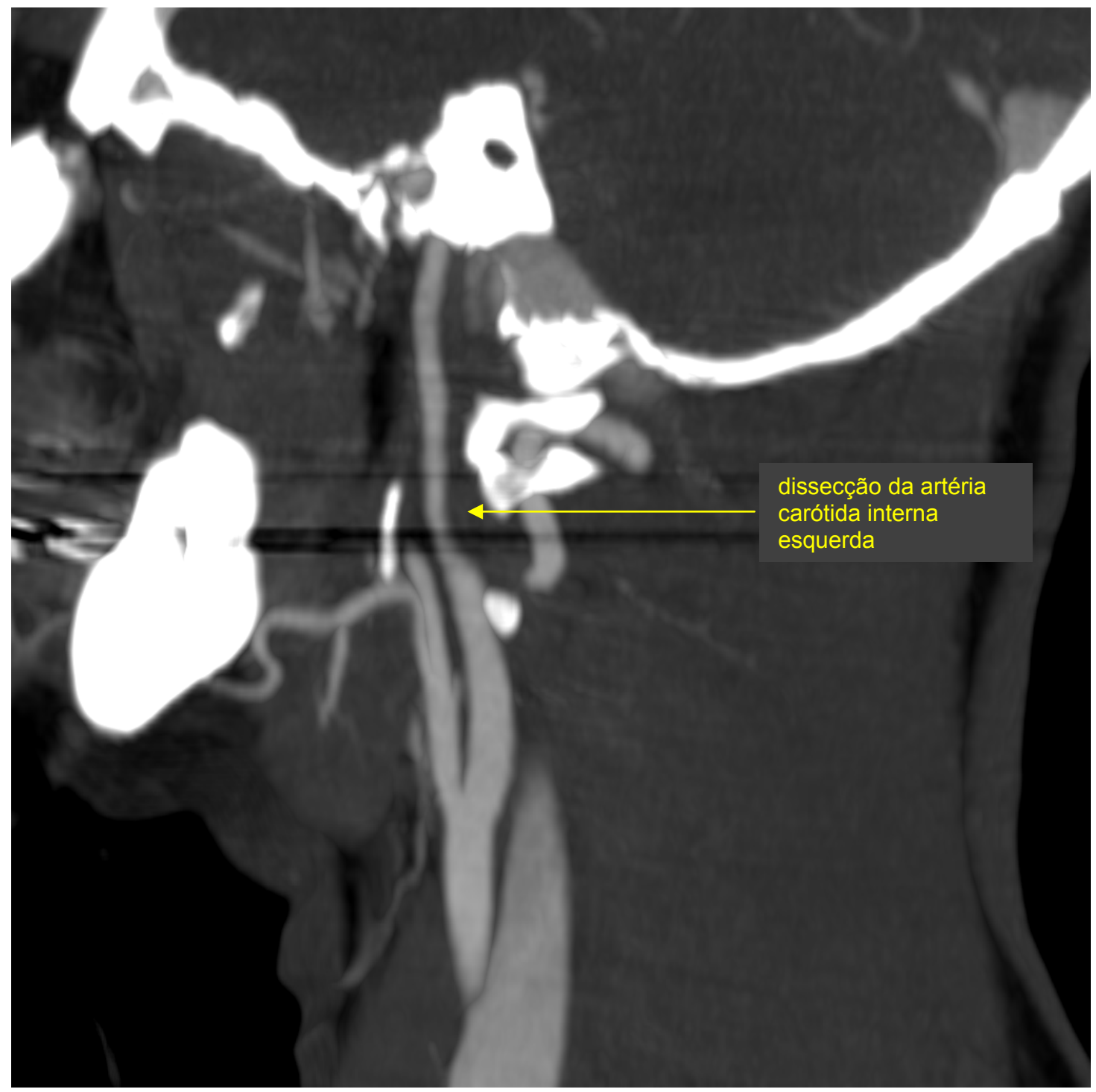

Figura 11B Angiotomografia dos vasos cervicais em reconstrução sagital identificando a artéria carótida interna esquerda com dissecção maior que $25 \%$ à esquerda 


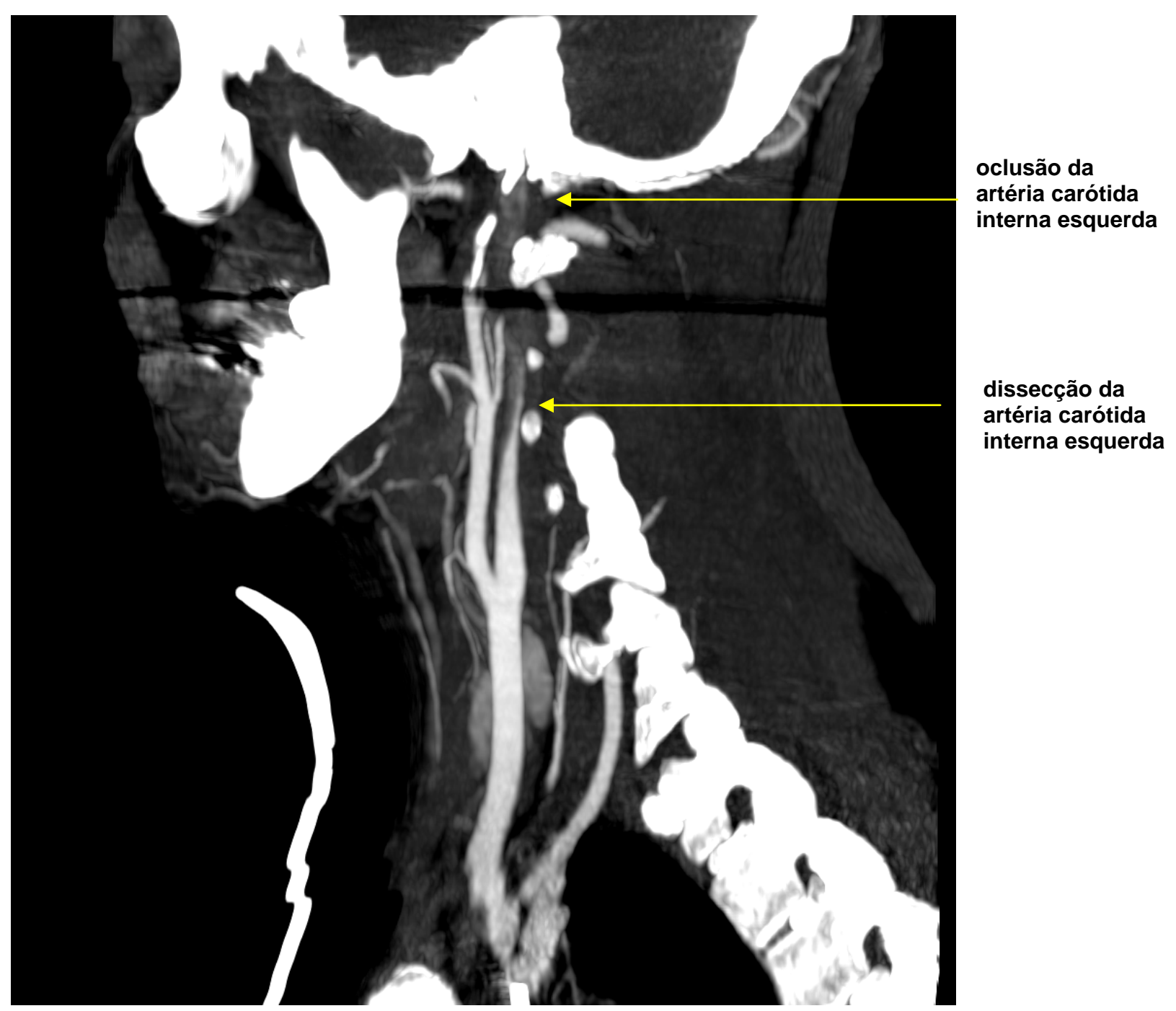

Figura 12A - Angiotomografia dos vasos cervicais: oclusão e dissecção da artéria carótida interna esquerda a partir do seu terço médio com oclusão distal. 


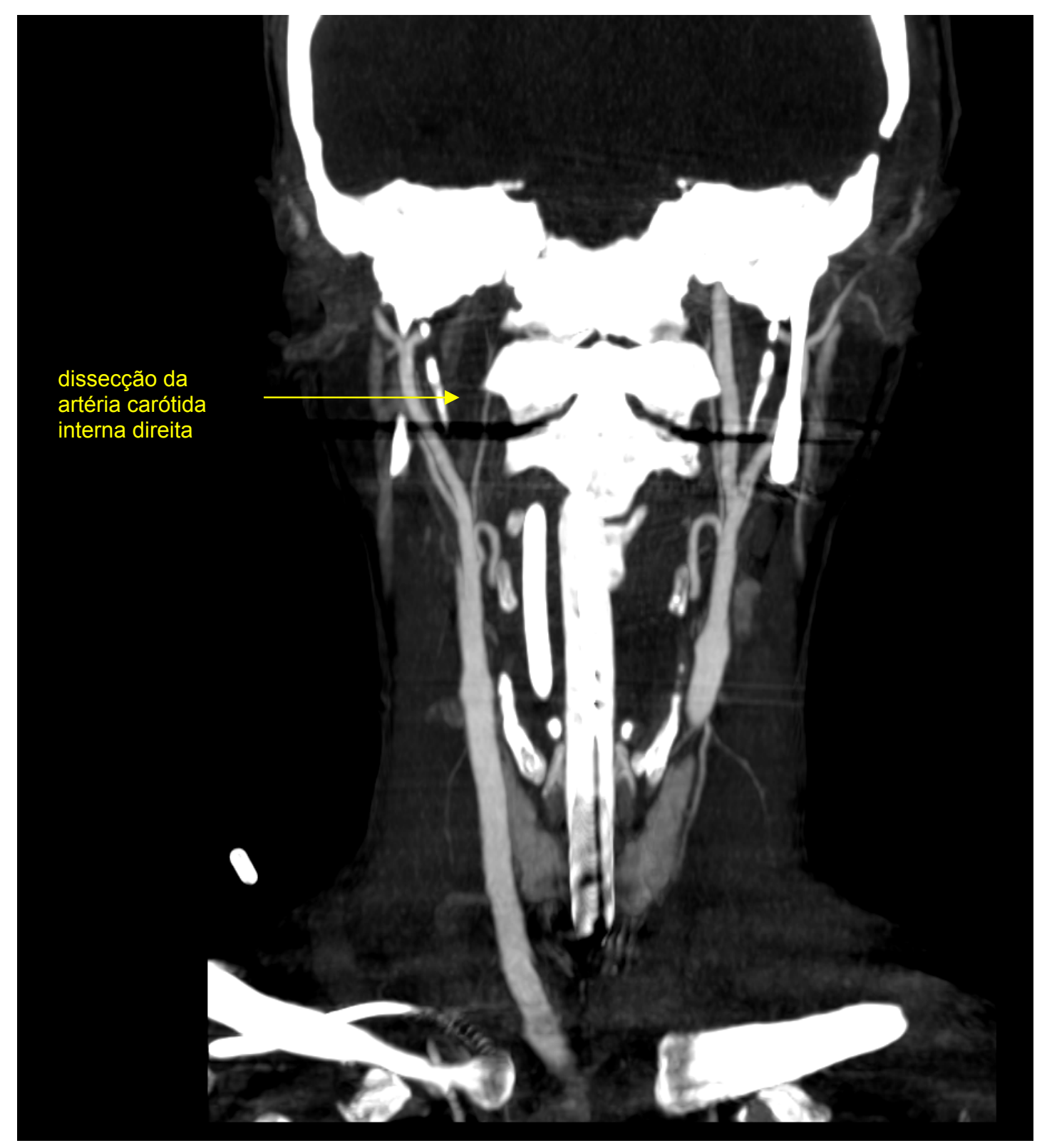

Figura 12B - Angiotomografia Cervical com dissecção da artéria carótida interna direita 


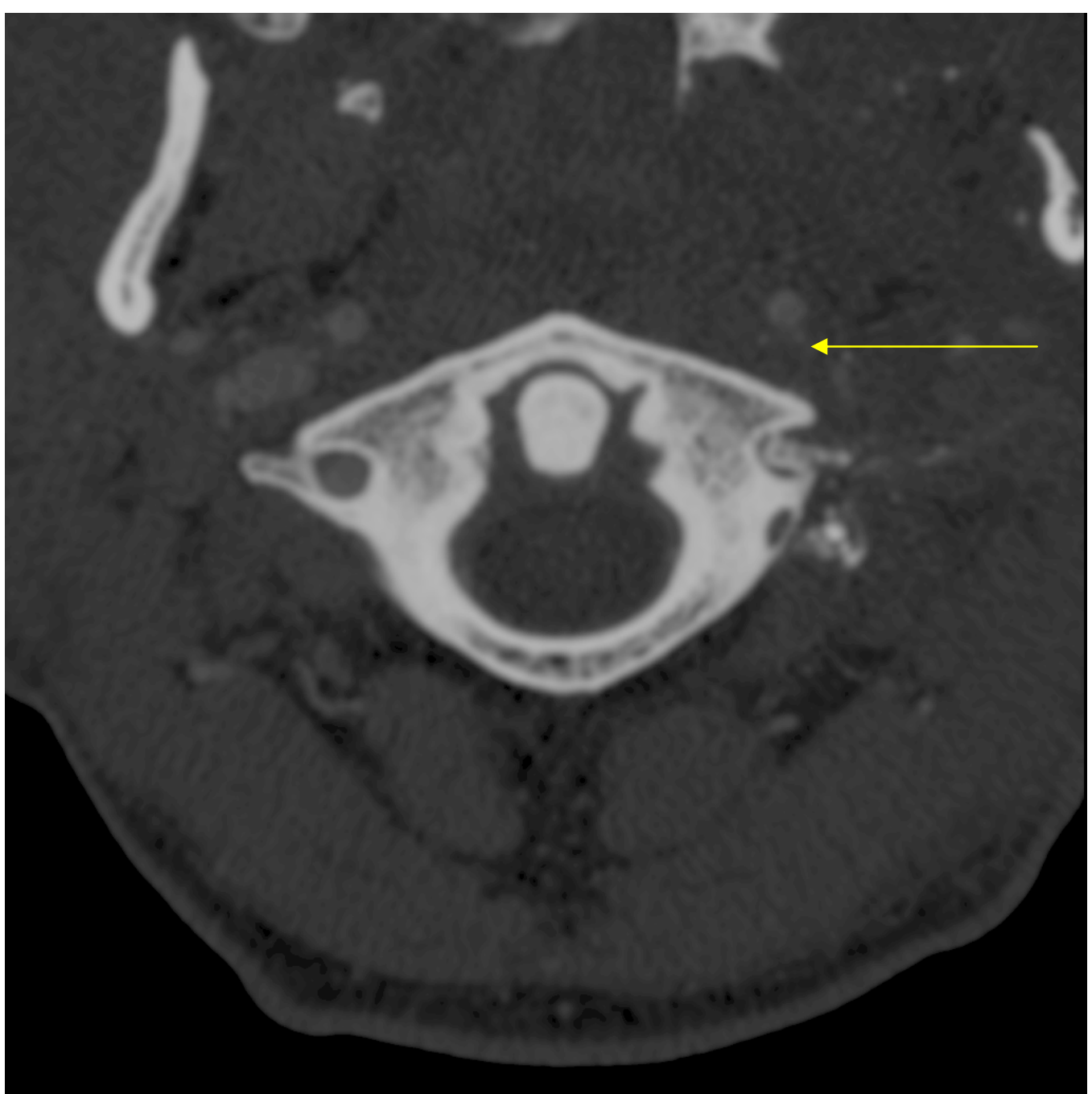

Figura 13A - Angiotomografia Cervical (janela óssea), corte axial identificando fragmento ósseo no interior do forame transverso esquerdo (seta) 


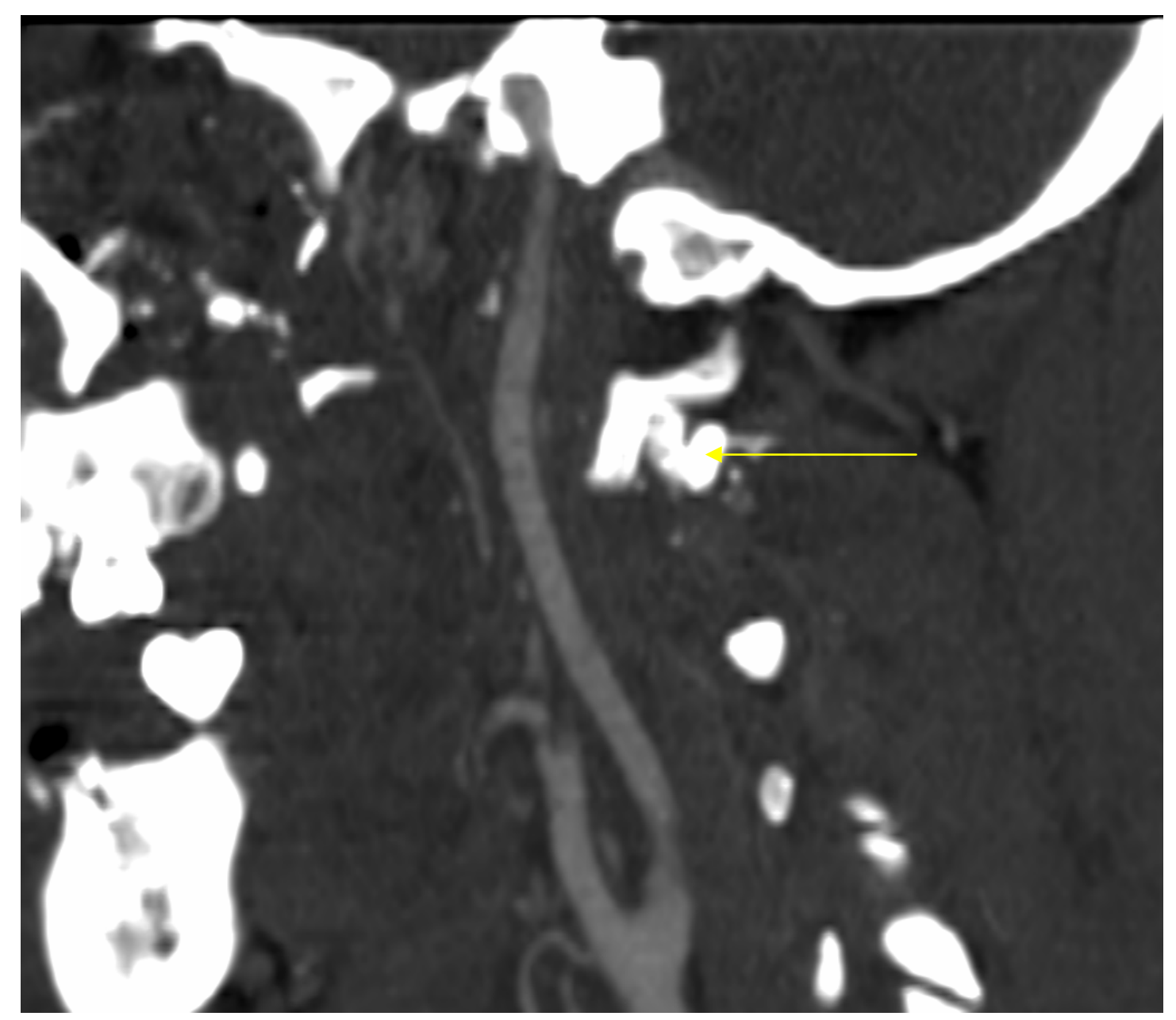

Figura 13B - Angiotomografia Cervical em reconstrução sagital com dissecção e oclusão da artéria vertebral esquerda (seta) 


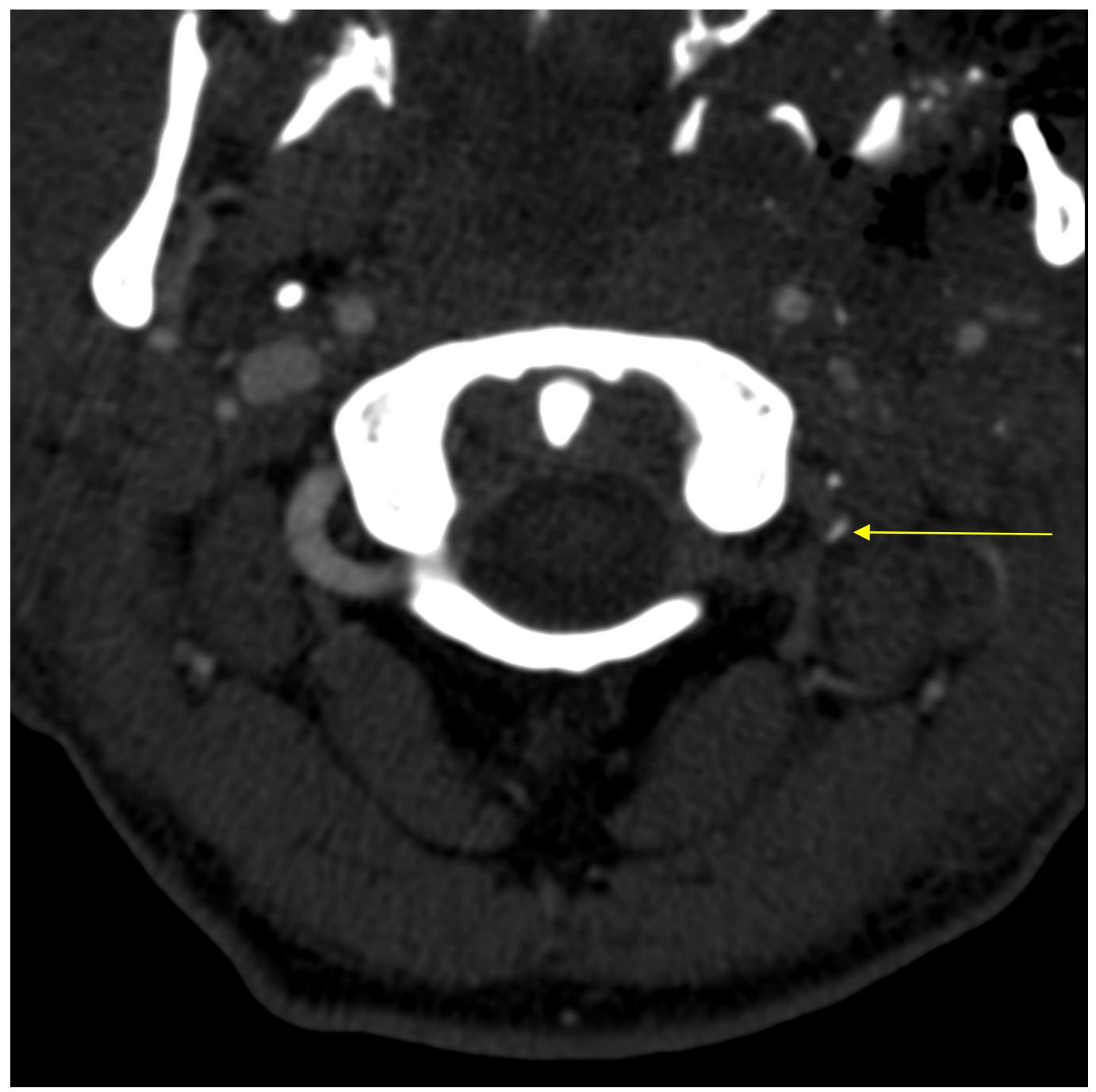

Figura 13C- Angiotomografia Cervical com corte axial nível imediatamente acima da transecção, não demonstrando a artéria vertebral esquerda neste nível (seta) 


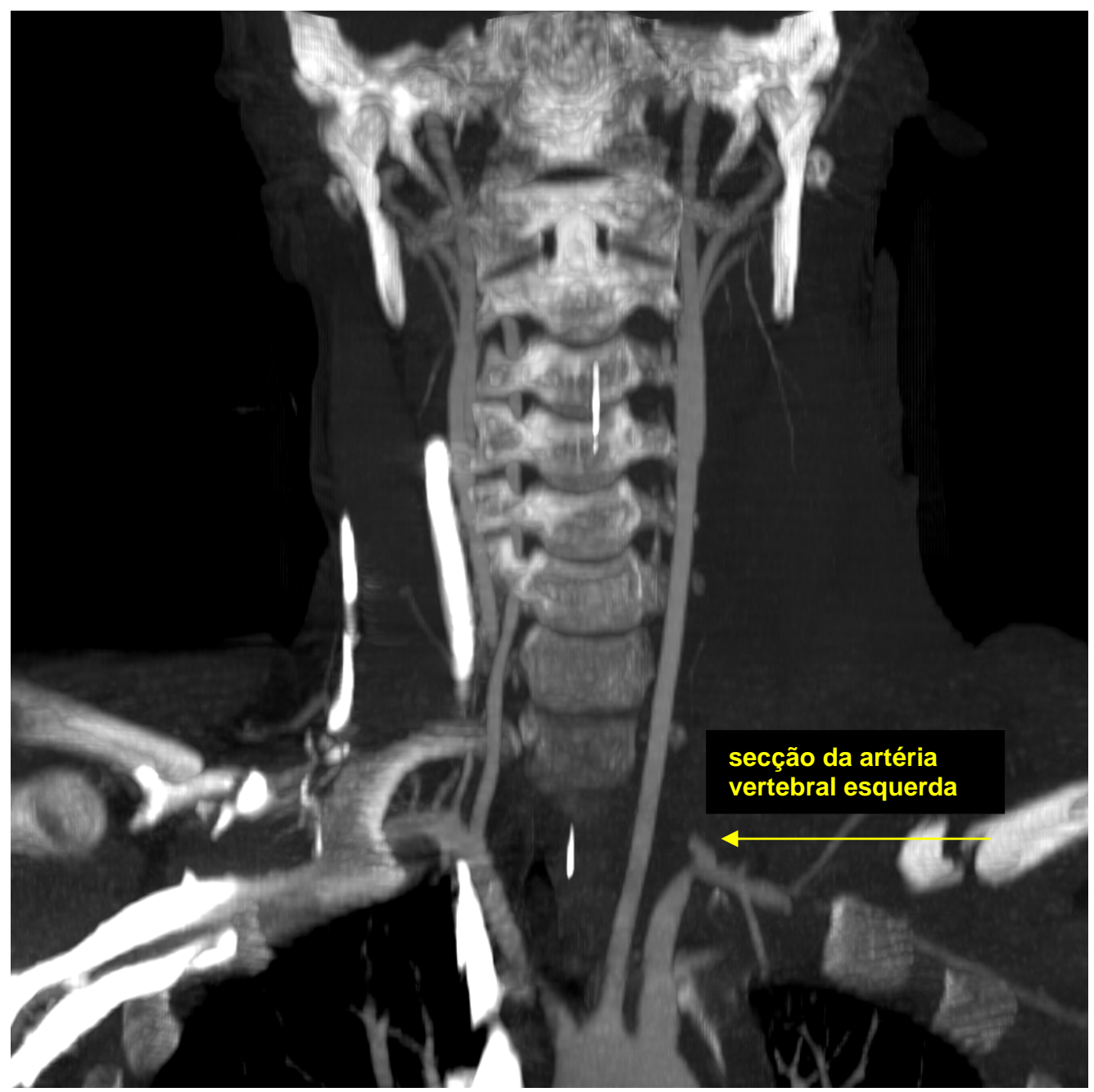

Figura 14 - Angiotomografia Cervical identificando secção da artéria vertebral esquerda próxima da sua origem 
McKinney et col. em estudo de 24 doentes portadores de leões de carótidas e vertebrais encontraram 10 doentes com lesões Grau I, 4 doentes com lesões Grau II, oito doentes com lesões Grau III, dois doentes com lesões Grau IV e nenhum doente com lesão $G r a u ~ V{ }^{(20)}$. No presente trabalho, verificamos sete doentes com lesões Grau I; dez, com lesões Grau II; nenhum com lesão Grau III, quatro doentes com lesões Grau IV, um com lesão Grau V e um com fístula.

Para efetuar um bom tratamento de LCCV é imprescindível identificar a lesão na admissão hospitalar do traumatizado, conhecer sua localização exata, classificar o melhor possível o tipo de lesão arterial, para então aplicar o tratamento ideal. O sucesso do tratamento fica na dependência da possibilidade de se reduzir ao máximo os riscos de embolia e ou episódio isquêmico provocado pela oclusão ou estenose importante. O tratamento pode ser clínico, com ou sem medicamentos ou cirúrgico por técnica aberta ou abordagem endovascular, utilizando embolização ou colocação de stent.

As oclusões arteriais são, frequentemente, bem toleradas quando o polígono de Willis estiver pérvio e permitir a circulação arterial adequada. Os exames de imagem podem identificar a permeabilidade deste polígono.

Exames que avaliam a perfusão cerebral, também, podem dar uma ideia do estado de perfusão do hemisfério cerebral do mesmo lado da lesão arterial. Caso o doente não tolere a redução da perfusão advinda da lesão arterial, algum procedimento de revascularização deve ser feito, seja ele cirúrgico ou endovascular. Os recursos endovasculares podem oferecer 
revascularização imediata. As vantagens da abordagem endovascular são as seguintes: tratamento imediato, preservação da permeabilidade da artéria, possibilidade de utilização de anestesia local, recuperação rápida, diminuição do índice de lesões por dissecções cirúgicas e possibilidade de ação em locais de difícil acesso cirúrgico (zonas cervicais I ou III). Dentre as desvantagens da abordagem endovascular, lembramos o uso de antiagregante plaquetário e um pequeno número de casos de seguimento a longo prazo.

Caso o doente tolere a oclusão arterial provocada pelo trauma, o tratamento medicamentoso pode ser usado para previnir fenômenos tromboembólicos. Desde que não exista contra indicação, podem ser usados anticoagulantes e/ou antiagregantes plaquetários. Estes medicamentos reduzem a formação de coágulos no local do trauma vascular e permitem a ação do sistema fibrinolítico, evitando, assim, a embolização de coágulos. As dissecções com ou sem formação de pseudoaneurismas podem ser tratadas por observação clínica, anticoagulação, reconstrução cirúrgica ou técnica endovascular.

No trabalho de Fabian et col., 67 doentes com 87 lesões de carótida, incluindo, 54 dissecções, 11 pseudoaneurismas com dissecções, 17 tromboses, 4 fístulas carotido-cavernosas e uma transecção foram tratadas da seguinte forma: as fístulas foram embolizadas com balão, a transecção foi ligada, 47 doentes foram tratados com heparina, 8 foram apenas observados, 6 receberam aspirina e um foi submetido à cirurgia. Nesse estudo, o grupo de doentes que recebeu heparina apresentou melhor evolução do que os que não receberam heparina. As complicações dos que receberam heparina foram as 
seguintes: hemorragia gastrointestinal, hemorragia de lesão hepática, hemorragia traqueal, dois hematomas subdurais que necessitaram de cirurgia e um agravamento de hemorragia ventricular. Posteriormente, 39 doentes foram reexaminados, identificando-se $62 \%$ de normalização da lesão e $29 \%$ de desenvolvimento de pseudoaneurisma ${ }^{(3)}$.

Biffl et col. identificaram 114 doentes com 157 lesões das artérias carótidas e 79 doentes com 97 lesões das artérias vertebrais, assim, 137 lesões eram Grau I; 52, Grau II; 32, III; 25, IV e oito Grau V. Uma semana após o trauma, 114 lesões de carótida e 65 lesões vertebrais foram reavalidas com arteriografia e $82 \%$ das lesões Grau IV e 93\% das lesões Grau III não apresentaram modificações. Por outro lado, 57\% das lesões Grau I e $8 \%$ das lesões Grau II regrediram para a normalidade total, permitindo a interrupção do tratamento. Assim, oito por cento das lesões Grau I e 43\% das lesões Grau II pioraram desenvolvendo pseudoaneurisma, exigindo tratamento intervencionista. Os autores concluem que o acompanhamento com a arteriografia pode modificar o tratamento em até $61 \%$ das lesões Grau I e II (21).

Cothren et col., em 2005, publicaram um estudo prospectivo e verificaram que os doentes que apresentavam pseudoaneurisma de carótida e foram tratados com stent, tiveram $21 \%$ de complicações com oclusão de até $45 \%$. Ao contrário, os que foram tratados com agente antitrombolítico, tiveram cinco por cento de oclusão da artéria. Nenhum doente assintomático teve obstrução de artéria com esta medicação. Concluem que o tratamento com 
agentes antitrombóticos permanece como a melhor opção terapêutica e que o uso de stent ainda é controverso ${ }^{(22)}$.

Por outro lado, Berne et col., em 2008, defendem o uso do stent na artéria carótida por ser efetivo e seguro, como terapia inicial para doentes com pseudoaneurisma e sem obstrução de carótida. A incidência de morbidade até 4 anos foi muito pequena ${ }^{(23)}$.

A habilidade na condução do tratamento para melhorar os resultados neurológicos é um desejo de todas as equipes de trauma, porém, cada doente apresenta alguma complexidade clínica. Em nosso estudo, 15 doentes foram submetidos ao tratamento com heparina (cinco com heparina não fracionada e dez fracionada). Dos três doentes que morreram, dois foram por morte encefálica. Dos oito doentes que não trataram com heparina, quatro morreram, e dois foram por infarto cerebral. Dois doentes foram observados clinicamente e seis doentes foram submetidos ao tratamento endovascular. Resumindo, 17 doentes foram tratados clinicamente e seis foram tratados com técnica endovascular. Não foi identificada nenhuma complicação no tratamento clínico com heparina ou endovascular.

As melhores decisões ficam por conta da experiência do médico e do serviço, bem como do estado clínico e neurológico do doente.

Em síntese, os resultados do presente estudo indicam que:

1- a incidência de lesões das artérias carótidas e vertebrais no trauma contuso foi de $0,93 \%$. 
2- os doentes portadores de lesões das artérias carótidas e vertebrais apresentam índice de gravidade maior do que os que não possuem essas lesões, mas mostram taxa de mortalidade semelhante.

3- em nosso meio, até o momento não foi possível estabelecer um critério que predomine em relação aos outros dez utilizados para indicação de investigação por método de imagem. 
6 Conclusões 
Com base nos resultados do presente estudo, pode-se concluir que, embora não haja consenso sobre quais critérios devam ser usados para indicação de angiotomografia para diagnóstico de LCCV no trauma, os critérios utilizados permitiram o diagnóstico de $0,93 \%$ dos casos numa população de 2467 doentes traumatizados, sendo que as lesões ocorreram nos traumatizados mais graves, e não influenciaram a mortalidade. 
7 Anexos

(2) 


\section{Anexo 1 - Aprovação pela Comissão de Ética para Análise de Projetos de Pesquisa - CAPPesq - Hospital das Clínicas da Faculdade de Medicina da Universidade de São Paulo}

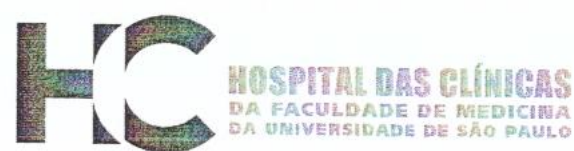

\section{APROVAÇÃO}

A Comissão de Ética para Análise de Projetos de Pesquisa - CAPPesq da Diretoria Clínica do Hospital das Clínicas e da Faculdade de Medicina da Universidade de São Paulo, em sessão de 02/04/2008, APROVOU o Protocolo de Pesquisa n 1187/07, intitulado: "TRAUMA CONTUSO DE VASOS CERVICAIS" apresentado pelo Departamento de CIRURGIA, inclusive o Termo de Consentimento Livre e Esclarecido.

Cabe ao pesquisador elaborar e apresentar à CAPPesq, os relatórios parciais e final sobre a pesquisa (Resolução do Conselho Nacional de Saúde n 196, de 10/10/1996, inciso IX.2, letra "c").

Pesquisador (a) Responsável: PROF. DR. RENATO SÉRGIO POGGETTI Pesquisador (a) Executante: DR. GLADSTONE GOULART

CAPPesq, 09 de Abril de 2008

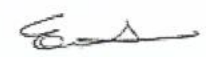

Prof. Dr. Eduardo Massad Presidente da Comissão de Ética para Análise de Projetos de Pesquisa 


\section{Anexo 2 - Termo de Consentimento Livre e Esclarecido}

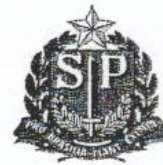

HOSPITAL DAS CLÍNICAS

DA FACULDADE DE MEDICINA DA UNIVERSIDADE DE SÃo PAULO

CAIXA POSTAL, 8091 - SÃo PAULO - BRAsIL

TERMO DE CONSENTIMENTO LIVRE E ESCLARECIDO

(Instruções para preenchimento no verso)

I - DADOS DE IDENTIFICAÇÃO DO SUJEITO DA PESQUISA OU RESPONSÁVEL LEGAL

1. NOME DO PACIENTE :

DOCUMENTO DE IDENTIDADE N' $:$ SEXO : M $\square F$
DATA NASCIMENTO:
ENDEREÇO
BAIRRO:
CEP

II - DADOS SOBRE A PESQUISA CIENTÍFICA

1. TÍTULO DO PROTOCOLO DE PESQUISA Diagnóstico da lesão de vasos cervicais no trau cervical contuso.

PESQUISADOR:Dr.GLADSTONE GOULART

CARGO/FUNÇĀO: MÉDICO

INSCRIÇÃO CONSELHO REGIONAL N ${ }^{\circ} 83716$

UNIDADE DO HCFMUSP: CLÍNICA CIRÚRGICA-CIRURGIA DO TRQAUMA

3. AVALIAÇÃO DO RISCO DA PESQUISA:

$\begin{array}{llll}\text { SEM RISCO } & \square & \text { RISCO MINIMO } X & \text { RISCO MÉDIO } \\ \text { RISCO BAIXO } & \square & \text { RISCO MAIOR } \quad \square & \end{array}$

(probabilidade de que o individuo sofra algum dano como consequência imediata ou tardia do estudo)

4.DURAÇÃO DA PESQUISA : DOIS ANOS 


\section{III - REGISTRO DAS EXPLICAÇÕES DO PESQUISADOR AO PACIENTE OU SEU REPRESENTAN" LEGAL SOBRE A PESQUISA CONSIGNANDO:}

1. justificativa e os objetivos da pesquisa. Identificar e avaliar as lesões nas artérias do pescoço(caróti e vertebral) em trauma contuso. $\mathrm{O} \mathrm{Sr}$ ou a $\mathrm{Sr}^{\mathrm{a}}$ foi vítima de um acidente que atingiu o seu pesco e existe a possibilidade de ter havido lesão dos vasos sangüíneos neste local. Se houver lesã ela não for diagnosticada, poderá haver conseqüências graves. Por isso, precisamos fazer algı exame para diagnosticar a possivel lesäo. Os exames comuns para esta situação(Rx, etc), deixi passar muitos casos sem identificar a lesão. Existem dois exames para casos como o si Arteriografia e Angiotomografia. Como a arteriografia é mais agressiva, necessitando de color um cateter por dentro da artéria, a angiotomografia por sua vez, só injeta contraste na veia braço. Este procedimento, a angiotomografia, é feito nos Estados Unidos da América do Nortı em outros países. Agora, já está sendo feito aqui no Hospital das Clínicas. Como é um exal relativamente novo e precisamos documentar bem os casos estudados, necessitamos do $s$ consentimento para fazermos a angiotomografia no senhor.

2. procedimentos que serão utilizados e propósitos, incluindo a identificação dos procedimentos que s experimentais. Angiotomografia para identificação de lesão dos vasos sanguíneos no pescoçı Arteriografia na vigência de lesão para fins de tratamento.

3. desconfortos e riscos esperados. O desconforto da angiotomografia é semelhante ao de levar u picada de injeção na veia, com riscos mínimos $\mathrm{p} /$ o paciente.

4. benefícios que poderão ser obtidos. Identificação da lesão de imediato, possibilitando o tratame| através de um cateter na veia à seguir ou dispensando a arteriografia se for negativo.

5. procedimentos alternativos que possam ser vantajosos para o individuo. A arterigrafia é o exame pad ouro que, deverá ser feito após ídentificação da lesão da artéria carótida e ou vertebral a fim estudar qual o melhor tratamento clínico ou cirúgico. A angiotomografia representa a alternaf mais moderna visando evitar a arteriografia nos casos em que ela é negativa.

\section{IV - ESCLARECIMENTOS DADOS PELO PESQUISADOR SOBRE GARANTIAS DO SUJEITO DA PESQUISA CONSIGNANDO:}

1. acesso, a qualquer tempo, às informações sobre procedimentos, riscos e beneficios relacionado pesquisa, inclusive para dirimir eventuais dúvidas.

2. liberdade de retirar seu consentimento a qualquer momento e de deixar de participar do estudo, sem isto traga prejuizo à continuidade da assistência. 
3. salvaguarda da confidencialidade, sigilo e privacidade. Isto será informado e esclarecido ao paciente

4. disponibilidade de assistência no HCFMUSP, por eventuais danos à saúde, decorrentes da pesquisa. Isto será informado e esclarecido ao paciente.

5. viabilidade de indenização por eventuais danos à saúde decorrentes da pesquisa.

Embora o procedimento (Angiotomografia) tenha menos riscos do que a Arteriografia, procedimentos tem seus riscos e não há viabilidade de indenização.

V. INFORMAÇÕES DE NOMES, ENDEREÇOS E TELEFONES DOS RESPONSÁVEIS PELO ACOMPANHAMENTO DA PESQUISA, PARA CONTATO EM CASO DE INTERCORRÊNCIAS CLÍNIC E REAÇÕES ADVERSAS.

VI. OBSERVAÇÕES COMPLEMENTARES:

\section{VII - CONSENTIMENTO PÓS-ESCLARECIDO}

Declaro que, após convenientemente esclarecido pelo pesquisador e ter entendido o que me foi explic consinto em participar do presente Protocolo de Pesquisa

São Paulo, de de 19 
Anexo 3 - Protocolo de identificação do doente com risco de lesão de vasos cervicais em trauma contuso

Data-

$\mathrm{N}^{\circ}$ Prontuário

Nome

Idade- Sexo- $\square \mathrm{M} \quad \square \mathrm{F}$

Mecanismo de Trauma:

$\square$ colisão de moto $\square$ colisão de auto $\square$ atropelamento $\square$ queda de grande altura

$\square$ outros (especificar)

PA - $\quad \mathrm{Fr}-\quad \mathrm{FC}$ -

Índices de Trauma - RTS- ISS-

TRISS-

Escore na escala de coma de Glasgow -

\section{Critérios de Inclusão}

- Lateralização de déficit neurológico não justificado na tomografia

$\square$ Infarto cerebral identificado na tomografia

$\square$ Hematoma cervical (não expansível)

Epistaxe volumosa

$\square$ Anisocoria/ sinal de Horner

- Fratura da base de crânio

G Glasgow <8 - Sem achados justificativos na tomografia de crânio

$\square$ Fratura da vértebra cervical

- Trauma de face (LeFort II ou LeFort III)

- Sinal do cinto de segurança acima da clavícula

$\square$ Frêmito ou sopro em região cervical

\section{Manifestação Clínica:}


Método de Imagem - $\square$ Angiotomografia $\quad \square$ Tomografia $\quad \square R X \quad \square$ Doppler

\begin{tabular}{|c|c|c|c|c|}
\hline \multirow[t]{3}{*}{ Lesão vascular - } & $\square$ Carótida & $\square$ comum D & $\square$ interna D & $\square$ externa D \\
\hline & & $\square$ comum E & $\square$ interna $E$ & $\square$ externa \\
\hline & Vertebral & Direita & Esquerda & \\
\hline
\end{tabular}

\section{Grau de Lesão:}

Grau I - Irregularidade da luz arterial ou dissecção com <25\% de estreitamento

Grau II - Dissecção ou hematoma intramural com $\geq 25 \%$ de estreitamento da luz arterial trombo intramural

G Grau III - Pseudoaneurisma

$\square$ Grau IV - Oclusão arterial

G Grau V- Transecção com hemorragia

\section{Tratamento}

Clínico (anticoagulação) Droga e dosagem

Data:

口 Observação clínica

$\square$ Endovascular $\square$ Stent revestido - Tipo de material

- Embolização - Material

Intercorrência clínica -

Data:

Alta hospitalar - $\quad \square$ com sequela - Tipo

$\square$ sem sequela

口 Óbito - 


\section{Anexo 4 - Planilha dos dados clínicos dos 100 pacientes}

Legenda:

dsç = dissecção; tb = trombose; $h p n=$ heparina; hbpm = heparina de baixo peso molecular;

frac $=$ fracionada enxv $=$ enxerto venoso; aartb $=$ aneurisma artéria basilar; tsts $=$ trombo seio transverso-sigmóide; paarc = pseudo aneurisma artério-comunicante TRISS $\ldots . .$. 
8 Referências 
1 - Biffl WL, Moore EE, Offner PJ, Burch JM. Blunt carotid and vertebral arterial injuries. World J Surg. 2001;25:1036-1043.

2 - Miller PR, Fabian TC, Bee TK, Timmons S, Chamsuddin A, Finkle R, Croce MA. Blunt cerebrovascular injuries: diagnosis and treatment. J Trauma. 2001;51(2):279-286.

3 - Fabian TC, Patton JH Jr., Croce MA, Minardd G, Kudsk KA, Pritchard FE. Blunt carotid injury: importance of early diagnosis and anticoagulant therapy. Ann Surg. 1996;223:513.

4 - Punjabi AP, Plaisier BR, Haug RH, Malangoni MA. Diagnosis and management of blunt carotid artery injury in oral and maxillofacial surgery. J Oral Maxillofac Surg. 1997;55:1388.

5 - Ramadan F, Rutledge R, Oller D, Howell P, Baker C, Keagy B, Hill C. Carotid artery trauma: a review of contemporary trauma center experiences. J Vasc Surg. 1995;21:46.

6 - Martin RF, Eldrup-Jorgensen J, Clark DE, Bredenberg CE. Blunt trauma to the carotid arteries. J Vasc Surg. 1991;14:789. 
7 - Crissey MM, Bernstein EF. Delayed presentation of carotid intimal tear following blunt craniocervical trauma. Surgery. 1974;75:543.

8 - Zelenock GB, Kazmers A, Whithouse WM Jr., Graham LM, Erlandson EE, Cronenwett JL, Lindenauer SM, Stanley JC. Extracranial internal carotid artery dissections: noniatrogenic traumatic lesions. Arch Surg. $1982 ; 117: 425$

9 - Carter DA, Mehelas TJ, Savolaine ER, Dougherty LS. Basal skull fracture with traumatic polycranial neuropathy and occluded left carotid artery: significance of fractures along the course of the carotid artery. $\mathrm{J}$ Trauma. 1998;44:230.

10 - Biffl WL, Moore EE, Elliott JP, Brega KE, Burch JM. Blunt cerebrovascular injuries. Curr Prob Surg. 1999;36:507.

11 - Biffl WL, Egglin T, Benedetto B, Gibbs F, Cioffi WG. Sixteen-slice computed tomographic angiography is a reliable noninvasive screening test for clinically significant blunt cerebrovascular injuries. J Trauma. 2006;60(4):745-51.

12 - Biffl WL. Diagnosis of blunt cerebrovascular injuries. Curr Open Critic Care. 2003;9(6):530-4. 
13 - Miller PR, Fabian TC, Bee TK, Timmons S, Chamsuddin A, Finkle R, BA BS, Croce MA. Blunt Cerebrovascular Injuries: Diagnosis and Treatment. J Trauma. 2001;51(2):279-286.

14 - Biffl WL, Moore EE, Offtner PJ, Brega KE, Franciose RJ, Burch JM. Blunt carotid arterial injurries: implications of a new grading scale. $\mathrm{J}$ Trauma. 1999;47(5):845.

15 - Cothren CC, Moore EE, Biffl WL, Ciesia DJ, Ray CE Jr., Johnson JL, Moore JB, Burch JM. Cervical spine fracture patterns predictive of blunt vertebral artery injury. J Trauma. 2003;55(5):811-3.

16 - Miller PR, Fabian TC, Croce MA, Cagiannos C, Williams JS, Vang M, Qaisi WG, Felker RE, Timmons SD. Prospective screening for blunt cerebrovascular injuries: analysis of diagnostic modalities and outcomes. Ann Surg. 2002;236:386-395.

17 - LeBlang SD, Nunez DB Jr., Rivas LA, et al. Helical computed tomography angiography in penetrating neck trauma. Emerg Radiol. 1997;4:200-206.

18 - Munera F, Soto JA, Palacio D, Velez SM, Medina E. Diagnosis of arterial injuries caused by penetrating trauma to the neck: comparison 
of helical CT angiography and conventional angiography. Radiology. 2000;216:356-362.

19 - Rogers FB, Baker EF, Osler TM, Shackford SR, Wald SL, Vieco P. Computed tomographic angiography as a screening modality for blunt cervical arterial injuries: preliminary results. J Trauma. 1999;46:380385.

20 - McKinney A, Ott F, Short J, McKinney Z, Truwit C. Angiographic frequency of blunt cerebrovascular injury in patients with carotid canal of vertebral foramen fractures on multidetector CT. Eur J Radiol. 2007;62(3): 385-93.

21 - Biffl WL, Ray Jr. CE, Moore EE, Franciose RJ, Somer Aly S, Heyrosa MG, Johnson JL, Burch JM. Treatment-related outcomes from blunt cerebrovascular injuries - importance of routine follow-up arteriography. Ann Surg. 2002;235(5):699-707.

22- Cothren CC, Moore EE, Ray Jr CE, Ciesla DJ, Johnson JL, Moore JB, Burch JM. Carotid artery stents for blunt cerebrovascular injury - risks exceed benefits. Arch Surg. 2005; 140: 480-486.

23 - Berne JD, Reuland KR, Villareal DH, McGovern TM, Rowe SA, Norwood SH. Internal carotid artery stending for blunt carotid artery 
injuries with an associated pseudoaneurysm. J Trauma. 2008;64(2): 398-405. 